\title{
Currency Risk and Pricing Kernel Volatility
}

\author{
Federico Gavazzoni, ${ }^{*}$ Batchimeg Sambalaibat, ${ }^{\dagger}$ and Chris Telmer $^{\ddagger}$
}

November 2012

First Draft: November 2012

\begin{abstract}
A basic tenet of lognormal asset pricing models is that a risky currency is associated with a low pricing kernel volatility. Empirical evidence implies that a risky currency is associated with a relatively high interest rate. Taken together, these two statements associate high-interest-rate currencies with low pricing kernel volatility. We document evidence suggesting that the opposite is true. We approximate the volatility of the pricing kernel with the volatility of the short-term interest rate. We find that, across currencies, relatively high interest rate volatility is associated with relatively high interest rates. This contradicts the prediction of lognormal models. One possible reason is that our approximation of the volatility of the pricing kernel is inadequate. We argue that this is unlikely, in particular for questions involving currencies. We conclude that lognormal models of the pricing kernel are inadequate for explaining currency risk and that future work should place increased emphasis on distributions that incorporate higher moments.
\end{abstract}

\footnotetext{
*INSEAD; federico.gavazzoni@insead.edu

†Tepper School, Carnegie Mellon University; bsambala@andrew.cmu.edu

‡Tepper School, Carnegie Mellon University; chris.telmer@cmu.edu
} 


\section{Introduction}

Currency risk is tricky. Unlike many financial securities, volatility and risk can be very different things. Consider the following anecdote. Producers of apples and bananas face supply shocks. The supply shocks become manifest in the relative price of fruit, the cost of one banana in units of apples. The producers, therefore, face price risk ... a positive supply shock to apples decreases the relative price of apples. Now consider volatility. Suppose that the apple shocks are volatile relative to the banana shocks. Apple producers notice two things: (i) the relative price of bananas isn't doing them any favors; it goes down whenever they get a bad shock, (ii) the supply shocks that they face are dominating the variability in the relative price. These apple producers therefore view the price of bananas as being risky. If you offer them a derivative security that has its value tied to the price of bananas, they will demand a risk premium in order to buy it. Banana producers, of course, face a reciprocal sort of situation. They notice that the relative price of apples goes against them when they get a bad shock. However, because their shocks are relatively small, point (ii) doesn't really apply to them. Therefore, if you offer them a derivative security tied to the price of apples, they will demand a relatively small risk premium in order to buy it. Herein lies the tricky business. The high volatility commodity, apples, enjoys relatively low price risk.

If you replace apples and bananas with the marginal utility of the domestic and the foreign representative agent, and the relative price of bananas with the price of one euro in units of U.S. dollars, you now understand what currency risk is in any lognormal model. The country with the highly-volatile marginal utility will have the currency with the low risk premium (in fact, negative). Algebraically,

$$
E_{t} s_{t+1}-f_{t}=\frac{1}{2}\left(\operatorname{Var}_{t} \log m_{t+1}-\operatorname{Var}_{t} \log m_{t+1}^{*}\right)
$$

where $s_{t}$ and $f_{t}$ are the log spot and forward exchange rates (price of euros in units of dollars), $m_{t}$ is the nominal marginal rate of substitution of the U.S. representative agent, and $m_{t}^{*}$ is that of the European agent. The left-hand-side is the (continuously compounded) expected excess return on euros. We call it the currency risk premium. We call the nominal marginal rates of substitution, $m_{t+1}$ and $m_{t+1}^{*}$, the domestic and foreign pricing kernels. Equation (1) must hold in any complete-markets equilibrium in which things are (conditionally) lognormally distributed. $^{1}$

\footnotetext{
${ }^{1}$ Backus, Foresi, and Telmer (2001) page 287, Equation (14) (terse derivation below). More generally, Equation (1) must hold by virtue of no-arbitrage in the following sense. If one takes as given the process for $m_{t+1}$ (the existence of which is guaranteed by no-arbitrage), and the rate of currency depreciation, then no-arbitrage guarantees the existence of a unique process for $m_{t+1}^{*}$ such that, with conditional lognormality, Equation (1) must necessarily hold. Alternatively, take as given the set of all (no-arbitrage) pricing kernels, $m$ and $m^{*}$, for, respectively, payoffs
} 
Equation (1) says that if the dollar pricing kernel, $m_{t+1}$, has relatively high volatility, then the dollar will exhibit low risk in that its expected excess return over the euro will be negative. In more common language, the carry-trade funding (recipient) currencies are predicted to be those associated with high-(low)-volatility pricing kernels. This is the restriction that we seek to evaluate. Is currency risk the reciprocal of pricing kernel volatility?

Figure 1

Currency Risk and Return

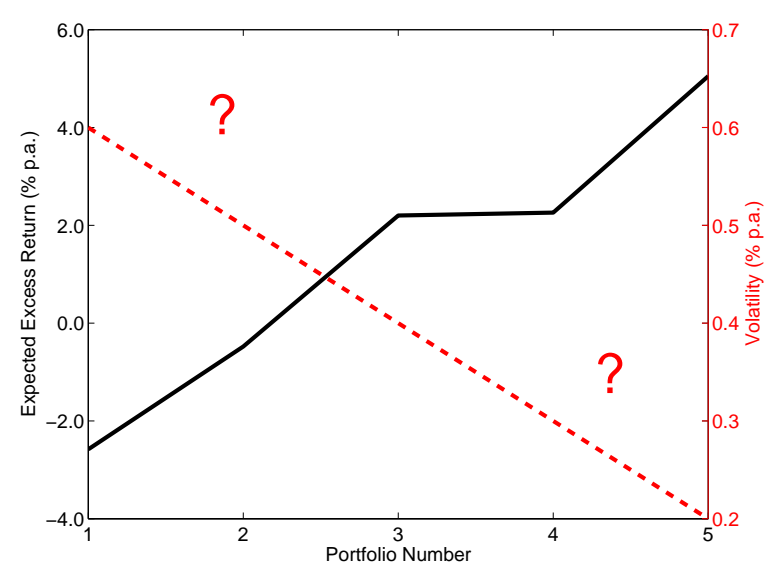

\begin{abstract}
The solid black line (left axis) reports the sample mean of the excess return on 5 interest-rate sorted currency portfolios, similar to that reported in Lustig, Roussanov, and Verdelhan (2011). The red dashed line (right axis) is, qualitatively, what lognormal pricing kernel models predict that pricing kernel volatility should look like.
\end{abstract}

Figure 1 illustrates our question graphically. It is an adaptation of Table 1 from Lustig, Roussanov, and Verdelhan (2011) (LRV). We construct five portfolios of currencies by constructing a monthly sort by the level of interest rates. Figure 1 reports the annualized average excess return, vis-a-vis the U.S. dollar, on each of the currency portfolios. We see what LRV, Burnside, Eichenbaum, Kleshchelski, and Rebelo (2011) and many others have documented; the 'carry-trade' of funding a long-position in a high-interest-rate currency by borrowing in a low-interest-rate

denominated in domestic and foreign currency units. Backus, Foresi, and Telmer (2001) (page 284, Proposition 1 and subsequent discussion) show that within the Duffie and Kan (1996) class of affine term structure models all members of this set are observationally equivalent given data on interest rates and exchange rates. This renders irrelevant the distinction between complete and incomplete markets. Finally, Brandt, Cochrane, and Santa-Clara (2006) show that Equation (1) must hold if we interpret $m$ and $m^{*}$ to be the unique least-squares projections of the set of no-arbitrage pricing kernels onto the space spanned by bond payoffs in multiple currencies. Their result also demonstrates the sense in which complete markets is not required for Equation (1) to be legitimate. 
currency seems to pay a positive excess expected return. Our question, then, is this. If Figure 1 also plots, for each portfolio, the average pricing-kernel volatility of all the currencies in the portfolio, then, according to Equation (1), the line should be decreasing. Is it?

We find evidence suggesting that it is not. High expected return seems to be associated with high pricing kernel volatility. This implies one of two things. Either our method of computing the variances in Equation (1) is faulty, or there's something wrong with conditional lognormality. We argue that the latter is most likely. We conclude that models of currency risk should incorporate departures from lognormality. Our results are supportive of recent work by Brunnermeier, Nagel, and Pedersen (2008) and others that emphasize conditional skewness and leptokurtosis.

\section{Notation and Basic Approach}

The pricing kernel for claims denominated in U.S. dollars (USD) is $m_{t+1}$, so that $E_{t} m_{t+1} R_{t+1}=1$ for all (gross) USD-denominated asset returns, $R_{t+1}$ realized between dates $t$ and $t+1$. The analogous pricing kernel for claims denominated in foreign currency (say, British pounds, GBP) is $m_{t+1}^{*}$ and GBP-denominated returns are $R_{t+1}^{*}$. Both $m_{t}$ and $m_{t}^{*}$ exist by virtue of no-arbitrage. One period, continuously-compounded USD and GBP interest rates are $i_{t}$ and $i_{t}^{*}$ so that

$$
\begin{aligned}
i_{t} & =-\log E_{t} m_{t+1} \\
i_{t}^{*} & =-\log E_{t} m_{t+1}^{*} .
\end{aligned}
$$

The date- $t$ nominal spot exchange rate, USD per GBP, is $S_{t}$. Since the USD pricing kernel must also price USD-denominated returns on GBP-denominated assets, no-arbitrage implies that

$$
E_{t}\left(m_{t+1} \frac{S_{t+1}}{S_{t}} R_{t+1}^{*}\right)=1
$$

Since $E_{t} m_{t+1}^{*} R_{t+1}^{*}=1$, then, if markets are complete, ${ }^{2}$

$$
\frac{S_{t+1}}{S_{t}}=\frac{m_{t+1}^{*}}{m_{t+1}}
$$

This permits the (continuously-compounded) depreciation rate of USD to be written,

$$
s_{t+1}-s_{t}=\log m_{t+1}^{*}-\log m_{t+1},
$$

\footnotetext{
${ }^{2}$ For what we'll do, the complete markets assumption is actually not required. See the footnote in the introduction.
} 
where $s_{t} \equiv \log S_{t}$. The one-period forward exchange rate and its logarithm are $F_{t}$ and $f_{t}$. Subtract Equation (3) from Equation (2) and invoke covered interest parity, $f_{t}-s_{t}=i_{t}-i_{t}^{*}$ :

$$
f_{t}-s_{t}=-\log E_{t} m_{t+1}-\left(-\log E_{t} m_{t+1}^{*}\right) .
$$

Take the conditional mean of Equation (6), and subtract from it Equation (7):

$$
\begin{aligned}
E_{t} s_{t+1}-f_{t} & =\left(\log E_{t} m_{t+1}-E_{t} \log m_{t+1}\right)-\left(\log E_{t} m_{t+1}^{*}-E_{t} \log m_{t+1}^{*}\right) \\
& =\frac{1}{2}\left(\operatorname{Var}_{t} \log m_{t+1}-\operatorname{Var}_{t} \log m_{t+1}^{*}\right)
\end{aligned}
$$

where the last equation holds by virtue of the conditional lognormality of $m_{t}$ and $m_{t}^{*}{ }^{3} \quad$ It is the same as Equation (1) from the introduction. The LHS is the risk premium on $G B P$ : the (continuously-compounded) expected excess return on borrowing USD and investing the proceeds in GBP. The RHS says that, in this class of models, a necessary condition for GBP to be risky is that its pricing kernel exhibit relatively low volatility.

Note that a great deal of empirical work - from older papers such as Domowitz and Hakkio (1985) to newer papers such as Chernov, Graveline, and Zviadadze (2012) - has focused on the conditional variance of the exchange rate, $\operatorname{Var}_{t}\left(s_{t+1}-s_{t}\right)$. Similarly, Brunnermeier, Nagel, and Pedersen (2008) focus on $\operatorname{Skew}_{t}\left(s_{t+1}-s_{t}\right)$. While these moments are certainly interesting in-and-ofthemselves, the combination of Equations (6) and (8) indicate that they emphasize moments of the difference, whereas currency risk is more directly about the difference of the moments. Sorting this out (in a new way) is the focal point of our paper.

\subsection{A Very Rough Approximation}

Equation (8) tells us that the currency risk premium is the difference between two unobservable variables. Many papers, of course, have written down an explicit (lognormal) model of $m_{t}$ and $m_{t}^{*}$ under which this difference is a function of observables. A successful model has been one with an interest rate differential, $i_{t}-i_{t}^{*}$, that is negatively correlated with the volatility difference, $V a r_{t} \log m_{t+1}-V a r_{t} \log m_{t+1}^{*}$. Our goal, instead, is to derive an empirical measure of this variance difference that applies more generally than to just one, particular (lognormal) model. We begin with a very informal derivation, intended to get at the main idea. In the next section we provide a tight, formalized analysis showing that what we do here applies much more generally.

\footnotetext{
${ }^{3}$ Backus, Foresi, and Telmer (2001), page 286, Equation (12), shows the more general expression, involving higher-order moments. This will play a key role later, in Section \#.
} 
With lognormality, Equation (2) implies that the period-ahead domestic interest rate is

$$
i_{t+1}=-E_{t+1} \log m_{t+2}-\frac{1}{2} \operatorname{Var}_{t+1} \log m_{t+2} .
$$

Suppose that variation in conditional mean is relatively small. This is not as unreasonable as it might sound, at least for our question. Backus, Foresi, and Telmer (2001) show that Fama's (1984) necessary conditions for resolving the forward premium anomaly translate into conditions stating that 'variance in pricing kernel variance must be larger than variance in pricing kernel means.' Papers by ? and ? show that something similar is implied by the Campbell-Shiller, Fama-Bliss term structure regressions. Thus ignoring the first term in Equation (9) we have

$$
\operatorname{Var}_{t} i_{t+1} \approx \frac{1}{4} \operatorname{Var}_{t} \operatorname{Var}_{t+1} \log m_{t+2}
$$

Suppose that the conditional variance of the conditional variance isn't too different from the the conditional variance. For some processes, this is sensible. For example, for the canonical square-root process, $x_{t+1}=\mu+\varphi x_{t}+\sigma x_{t}^{1 / 2} \varepsilon_{t+1}$, we have that $\operatorname{Var}_{t} \operatorname{Var}_{t+1} x_{t+2}=\sigma^{2} \operatorname{Var}_{t} x_{t+1}=\sigma^{4} x_{t}$. For other processes - e.g., an autoregression with stochastic volatility, but where the volatility is homoskedastic - it makes no sense. Ignoring the latter,

$$
\operatorname{Var}_{t} i_{t+1} \approx \frac{1}{4} \operatorname{Var}_{t} \log m_{t+1}
$$

This is the main idea. Perhaps we can learn something about pricing kernel volatility by simply estimating interest rate volatility?

Suppose that this is valid. Substitute it into Equation (8):

$$
E_{t} s_{t+1}-f_{t} \approx 2\left(\operatorname{Var}_{t} i_{t+1}-\operatorname{Var}_{t} i_{t+1}^{*}\right) \text {. }
$$

In most lognormal models the LHS is a linear function of the interest rate differential:

$$
a+b\left(i_{t}-i_{t}^{*}\right) \approx 2\left(\operatorname{Var}_{t} i_{t+1}-\operatorname{Var}_{t} i_{t+1}^{*}\right)
$$

There is overwhelming empirical evidence indicating that $b<0$. This is the 'Uncovered Interest Rate Parity (UIP)' regression evidence first found by Bilson (1981), Fama (1984) and Tryon (1979). It is the basis for the foreign currency 'carry trade.' Assume that $a=0 .{ }^{4}$ Equation (11) implies that, according to lognormal models, (i) the interest rate differential, $i_{t}-i_{t}^{*}$ and the volatility differential,

\footnotetext{
${ }^{4}$ This is implied by the UIP evidence if (i) $b=-1$, (ii) UIP holds unconditionally, and (iii) the unconditional mean of the interest rate differential is zero, $E\left(i_{t}-i_{t}^{*}\right)=0$. For many currency pairs all of these conditions are empirically plausible (Engel (2011) provides some up-to-date evidence and his survey paper, Engel (1996), is a standard reference for a more exhaustive survey). For those for which they are not, our story is basically unchanged once we subtract out an innocuous mean.
} 
$V a r_{t} i_{t+1}-\operatorname{Var}_{t} i_{t+1}^{*}$, should have the opposite sign, and (ii) they should be negatively correlated.

Figure 3 shows results that are representative of our main findings. It shows that, for a classic 'carry trade' pair of currencies - USD and the Australian dollar (AUD) - restrictions (i) and (ii) seem to be strongly at odds with the data. Much more often than not, the LHS and RHS of Equation (11) have the same sign. Moreover, they are positively correlated at 0.52 .

Interest rate differentials and interest rate volatility differentials appear to be positively related. The high-interest rate currency - the carry-trade recipient currency that pays a positive risk premium - also appears to be the high interestrate-volatility currency. This isn't the case for every currency pair and time period but, as we exhaustively demonstrate in Section 5, it is much more the rule than the exception. Our approximation, Equation (10), suggests that we can restate this. The high-interest rate currency appears to be the high pricing-kernel-volatility currency. This is a stark contradiction of any lognormal model of currency risk.

We now tighten up the approximation from Section 2.1 and show precisely under what conditions high interest rate volatility is necessarily associated with high pricing kernel volatility.

\section{Affine Models}

The Duffie and Kan (1996) class of lognormal, affine pricing kernel models can be specified as follows. Uncertainty in the domestic country is described by the $k$-dimensional vector of state variables $z$ that follows a square-root model:

$$
z_{t+1}=(I-\Phi) \theta+\Phi z_{t}+\Sigma\left(z_{t}\right)^{1 / 2} \epsilon_{t+1}
$$

where $\{\epsilon\} \sim \operatorname{NID}(0,1), \Sigma\left(z_{t}\right)$ is a $k \times k$ diagonal matrix with a typical element given by $\sigma_{i}\left(z_{t}\right)=\alpha_{i}+\beta_{i}^{\top} z_{t}$, where $\beta_{i}$ has nonnegative elements, and $\Phi$ is a $k \times k$ stable matrix with positive diagonal elements. The process for $z$ requires that the volatility functions, $\sigma_{i}(z)$, be positive, which places additional restrictions on the parameters. The pricing kernel is

$$
-\log m_{t+1}=\delta+\gamma^{\top} z_{t}+\lambda^{\top} \Sigma\left(z_{t}\right)^{1 / 2} \epsilon_{t+1},
$$

where the $k \times 1$ vector $\gamma$ is referred to as the "factor loadings" for the pricing kernel, and the $k \times 1$ vector $\lambda$ is referred to as the "price of risk" vector.

Using Equation (2), together with the dynamics of the pricing kernel from Equation (12), the interest rate is

$$
i_{t+1}=\left(\delta-\frac{1}{2} \sum_{j=1}^{k} \lambda_{j}^{2} \alpha_{j}\right)+\left(\gamma^{\top}-\frac{1}{2} \sum_{j=1}^{k} \lambda_{j}^{2} \beta_{j}^{\top}\right) z_{t+1} .
$$


The conditional variance of the home pricing kernel is

$\operatorname{Var}_{t}\left(m_{t+1}\right)=\left(\lambda^{\top} \Sigma\left(z_{t}\right)^{1 / 2}\right) \operatorname{Var}_{t}\left(\epsilon_{t+1}\right)\left(\lambda^{\top} \Sigma\left(z_{t}\right)^{1 / 2}\right)^{\top}=\lambda^{\top} \Sigma\left(z_{t}\right) \lambda=\sum_{j=1}^{k} \lambda_{j}^{2} \sigma_{j}\left(z_{t}\right)$

and the conditional variance of the home interest rate is

$$
\begin{aligned}
\operatorname{Var}_{t}\left(i_{t+1}\right) & =\left(\gamma^{\top}-\frac{1}{2} \sum_{j=1}^{k} \lambda_{j}^{2} \beta_{j}^{\top}\right) \Sigma\left(z_{t}\right)\left(\gamma^{\top}-\frac{1}{2} \sum_{j=1}^{k} \lambda_{j}^{2} \beta_{j}^{\top}\right)^{\top} \\
& =\sum_{n=1}^{k}\left(\gamma_{n}-\frac{1}{2} \sum_{j=1}^{k} \lambda_{j}^{2} \beta_{n, j}\right)^{2} \sigma_{n}\left(z_{t}\right) .
\end{aligned}
$$

Similarly to the domestic country, the foreign country is described by a $k$-dimensional vector $z^{*}$. Foreign parameters are denoted with an asterisk. It is straightforward to derive the expressions for the foreign pricing kernel, $m^{*}$ and the foreign interest rate, $i^{*}$.

\subsection{Theorems}

Under what conditions can we say that

$$
\operatorname{Var}_{t}\left(m_{t+1}\right)>\operatorname{Var}_{t}\left(m_{t+1}^{*}\right) \Leftrightarrow \operatorname{Var}_{t}\left(i_{t+1}\right)>\operatorname{Var}_{t}\left(i_{t+1}^{*}\right) \quad ?
$$

The validity - or not - of result (13) is in general parameter dependent. However, for two special cases which are ubiquitous in the term structure and the currency risk premium literature, it turns out that we can say a fair bit.

\section{Theorem 1: Symmetric Coefficients}

Let $\Omega\left(\Omega^{*}\right)$ denote the vector containing the home (foreign) parameters. Let $\Omega=\Omega^{*}, \lambda \neq 0$ and $\left(\gamma^{\top}-\frac{1}{2} \sum_{j=1}^{k} \lambda_{j}^{2} \beta_{j}^{\top}\right) \neq 0$. Then $\left(\Sigma\left(z_{t}\right)-\Sigma\left(z_{t}^{*}\right)\right)$ is positive definite if and only if $\operatorname{Var}_{t}\left(m_{t+1}\right)>\operatorname{Var}_{t}\left(m_{t+1}^{*}\right)$, if and only if $\operatorname{Var}_{t}\left(i_{t+1}\right)>\operatorname{Var}_{t}\left(i_{t+1}^{*}\right)$.

The proof is in Appendix A. Theorem 1 says that, with symmetric coefficients, a relatively large conditional variance of the home state variables is associated with a relatively large conditional variance of the home pricing kernel and a relatively large conditional variance of the home interest rate. A given ranking in the conditional variance of the state variables in each country is associated with the same ranking 
in the conditional variance of the pricing kernels and the conditional variance of the interest rates.

As an example, consider the single-factor (per-country) case, $k=1$. Theorem 1 simplifies to

$$
\operatorname{Var}_{t}\left(z_{t+1}\right)>\operatorname{Var}_{t}\left(z_{t+1}^{*}\right) \Leftrightarrow \operatorname{Var}_{t}\left(m_{t+1}\right)>\operatorname{Var}_{t}\left(m_{t+1}^{*}\right) \Leftrightarrow \operatorname{Var}_{t}\left(i_{t+1}\right)>\operatorname{Var}_{t}\left(i_{t+1}^{*}\right)
$$

which can be read as "high conditional variance at home means high conditional variance in the home kernel and high conditional variance in the home interest rate."

\section{Theorem 2: Common Factors}

Consider the case of common factors, $z_{t}=z_{t}^{*}$. Assume that $\gamma=\gamma^{*}$, $\beta=\beta^{*}$, and that there exists a strong enough 'precautionary savings motive' associated with both the domestic and foreign pricing kernels, so that

$$
\gamma^{\top}-\frac{1}{2} \sum_{j=1}^{k} \lambda_{j}^{2} \beta_{j}^{\top}<0 \quad \text { and } \quad \gamma^{\top}-\frac{1}{2} \sum_{j=1}^{k}\left(\lambda_{j}^{*}\right)^{2} \beta_{j}^{\top}<0 .
$$

Suppose that the prices of risk $\lambda$ and $\lambda^{*}$ can be ordered, so that either $\lambda>\lambda^{*}$ or $\lambda<\lambda^{*}$. Then, $|\lambda|>\left|\lambda^{*}\right|$ if and only if $\operatorname{Var}_{t}\left(m_{t+1}\right)>$ $\operatorname{Var}_{t}\left(m_{t+1}^{*}\right)$ if and only if $\operatorname{Var}_{t}\left(i_{t+1}\right)>\operatorname{Var}_{t}\left(i_{t+1}^{*}\right)$.

The proof is in Appendix A. Theorem 2 says that, with common factors, a sufficient condition for the conditional variance of the domestic pricing kernel to be larger than the conditional variance of the foreign pricing kernel is that the price of risk of each of the home state variables is at least as large (in absolute value) than the price of risk of each of the foreign state variables. When this is the case, a strong enough precautionary saving demand in each country delivers a larger conditional variance of the home interest rate, relative to the conditional variance of the foreign interest rate. For the theorem to hold, symmetry in the factor loadings and in the sensitivity of the conditional variances to the state variables is required.

The condition that $\gamma^{\top}-\frac{1}{2} \sum_{j=1}^{k} \lambda_{j}^{2} \beta_{j}^{\top}<0$ (and its foreign counterpart) is usually referred to in the literature as a strong enough precautionary savings motive. Lustig, Roussanov, and Verdelhan (2011) is an example of Theorem 2 at work. They show that an affine model with a common factor, common coefficients across countries with the exception of the price of risk, and a precautionary saving motive that is strong enough in each country delivers interest rate and exchange rate dynamics that are consistent with the carry trade facts. Hence, the assumptions 
of Theorem 2 are not stringent at all. They must be satisfied for an affine model of the Duffie-Kan class to fit the data.

As an example, consider the single factor case, $k=1$. Here, a stronger result is available. Under the conditions of Theorem 2

$$
|\lambda|>\left|\lambda^{*}\right| \Leftrightarrow \operatorname{Var}_{t}\left(m_{t+1}\right)>\operatorname{Var}_{t}\left(m_{t+1}^{*}\right) \Leftrightarrow \operatorname{Var}_{t}\left(i_{t+1}\right)>\operatorname{Var}_{t}\left(i_{t+1}^{*}\right)
$$

where now $\lambda$ and $\lambda^{*}$ are scalars. In words, in a world with one single common factor, when all other coefficients are symmetric, having a relatively large home price of risk (in absolute value) means having a relatively high domestic kernel volatility and a relatively high interest rate volatility.

\section{Data and Estimation}

For our main analysis, we use data for 114 countries on 3-month treasury bill yields, forward and spot exchange rates from Global Financial Data (GFD) for the period 1950-2009. As a comparison, we also use eurocurrency interest rates for 27 countries from the Financial Times/ICAP (FT/ICAP), 1975-2009. Appendix $\mathrm{B}$ provides details. The number of countries is extensive, but, obviously, we do not have data for all countries and time periods, and the relevance of many of the countries for our question is questionable. We therefore report results for a number of different subsamples of time and country. Our main result is not sensitive to either.

We estimate a GARCH model for interest rate volatility. Details on the estimation procedure are given in Appendix B. We report results for both bilateral currency pairs and portfolios of currencies. The latter are formed in a manner identical to Lustig, Roussanov, and Verdelhan (2011), by sorting on interest rate levels at a monthly frequency. 


\title{
5 Results
}

In the introduction we used Figure 1 to illustrate our main question: is pricing kernel volatility decreasing in the interest rate differential, as lognormal theory predicts it should? Figure 2 answers our question. We conduct the exact same exercise as Lustig, Roussanov, and Verdelhan (2011). We sort currencies by interest rate and, each month, form 5 portfolios. Figure 2 plots the time-averaged excess return on each portfolio, and the time-averaged interest rate volatility. Both are increasing as we move from low to high interest rate portfolios. The answer to the question is no.

Figure 2

High Interest Rates are Associated with High Interest Rate Volatility

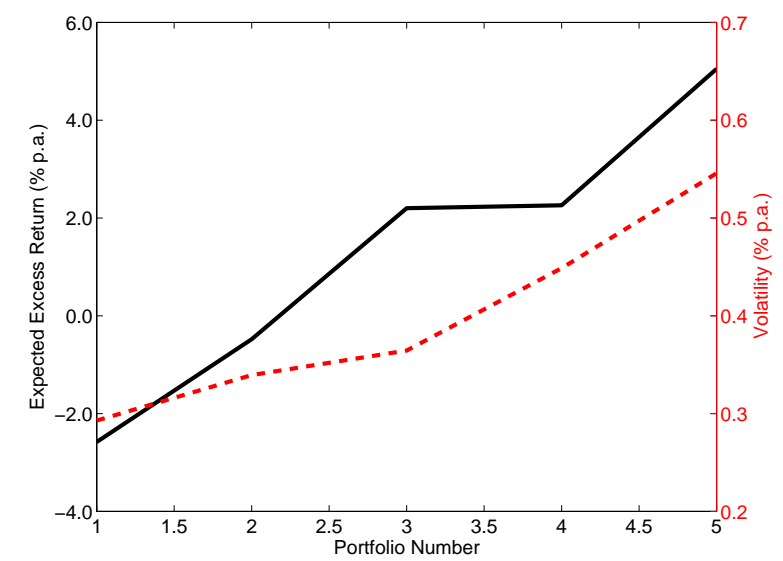

\begin{abstract}
The solid black line (left axis) is the same as that in Figure 1 from the introduction. It is the sample mean of the excess return on 5 interest-rate sorted currency portfolios, similar to that reported in Lustig, Roussanov, and Verdelhan (2011). The red dashed line (right axis) is, the time-averaged interest rate volatility on each of the portfolios. The class of lognormal models described in Section 3 restrict the red line to be decreasing if the black line is increasing. The data are, therefore, inconsistent with lognormal models in this dimension.
\end{abstract}

The remainder of our empirical work simply consists of further substantiating the point of Figure 2 by considering different samples and data sources. Figure 4 shows average volatility for the currency portfolios for a number of different subsamples, starting from 1950, 1975, 1987 and 1995. Figure 5 reports analogous results for bilateral currency pairs. Figure 6 compares results across the GFD and FT/ICAP data sources. In all cases, we see robust evidence of high interest rates differentials being associated with high interest rate volatility differentials. 


\section{Conclusions}

We have shown that Gaussian models of currency risk face an empirical challenge. A high interest rate differential seems to be associated with a high interest-rate volatility differential. In a broad class of Gaussian models of the pricing kernel, this is inconsistent with (i) the empirical observation that high interest rates are associated with high excess expected returns, and (ii) the theoretical restriction that high excess expected returns accrue to the low volatility pricing kernel. This inconsistency derives from some conditions under which interest rate volatility and pricing kernel volatility are positively related. These conditions are not exhaustive. But they are satisfied by some models that are prominent in the literature. This suggests that we either enrich these models, or consider non-Gaussian alternatives.

We've couched our analysis in terms of trying to observe directly the difference in the moments of pricing kernels. This stands in contrast to much existing work, which tends to be based on moments of the difference in pricing kernels (e.g., the variance of the exchange rate). We find our approach useful in that it emphasizes something fundamental about what currency risk is, while at the same time providing some links to other asset pricing models and results such as those from the literature on the term structure of interest rates. Nevertheless, we admit that ours does have the flavor of many previous papers that have gone searching for the unicorn by trying to identify the magical pricing kernel using very few assumptions and very little data (i.e., asset return data only). An alternative interpretation, therefore, is as follows.

Ever since Bilson (1981), Fama (1984) and Tryon (1979) discovered the existence of excess expected returns in currency markets, many models have been developed to account for this behavior. The first models focused almost exclusively on the UIP regression coefficient. For subsequent models the bar has been raised higher. Other moments of the joint distribution of exchange rates, interest rates, consumption and so on have been emphasized. Sharpe ratios on traded currency portfolios have been emphasized. Our results can be viewed as simply suggesting one more moment: the interest-rate volatility differential. There is clear evidence on this, and it places very binding restrictions on state-of-the-art models. More-

over, it seems (to us) to be a particularly important moment. There is a clear link to theory and this link might be pointing us to non-Gaussian behavior, something that has been strongly emphasized in the recent literature on crashes, disasters and the like. We like this moment.

Finally, we close with a broad, interpretive point. Currency risk is a particular type of "change of units risk." In Gaussian models, an inescapable characteristic of this is that high risk is associated with low volatility. If the units that I care about are subject to relatively volatile shocks, then financial securities with payoffs denominated in these units will pay a negative risk premium (relative to the other 
units in question). Our goal has been to ask if this characteristic fits the facts. To find out, one must first take a stand on what are "the units that I care about." The obvious answer (to an economist) is "real marginal utility units," where the word "real" makes clear that this is "marginal utility per unit of goods." We have circumvented this, focusing instead on nominal marginal utility units: "utils per dollar." We've done this because most financial securities are denominated in dollars, not in goods. We must therefore be silent on whether or not Gaussian models of real exchange rates fit the facts. But we can say something about nominal models, which, one-way-or-another, have been most prevalent in the literature. We find evidence suggesting that nominal exchange rate risk is more than just a Gaussian phenomenon. We also note that, while our data have not addressed them, Gaussian models of real marginal utility have become more and more prevalent in the literature ever since Hansen, Heaton, and Li (2008) developed their linearization of the recursive class of preferences. Much of the long-run risk literature initiated by Bansal and Yaron (2004) features models that are conditionally Gaussian. A prominent example featuring exchange rates is Bansal and Shaliastovich (2013). Our approach is easily applied in this setting, and will feature relative consumption volatility in addition to interest rate volatility. This is work-in-progress. 


\section{References}

Backus, David K., Silverio Foresi, and Christopher I. Telmer, 2001, Affine term structure models and the forward premium anomaly, Journal of Finance 56, 279-304.

Bansal, Ravi, and Ivan Shaliastovich, 2013, A long-run risks explanation of predictability puzzles in bond and currency markets, Review of Financial Studies $26,1-33$.

Bansal, Ravi, and Amir Yaron, 2004, Risks for the long run, a potential resolution of asset pricing puzzles, Journal of Finance 59, 1481-1509.

Bilson, John, 1981, The speculative efficiency hypothesis, Journal of Business 54, 435-452.

Brandt, Michael W., John H. Cochrane, and Pedro Santa-Clara, 2006, International risk sharing is better than you think, or exchange rates are too smooth, Journal of Monetary Economics 53, 671-698.

Brunnermeier, Markus K., Stefan Nagel, and Lasse Pedersen, 2008, Carry trades and currency crashes, NBER Macroeconomics Annual 23, 313-347.

Burnside, Craig, Martin Eichenbaum, Isaac Kleshchelski, and Sergio Rebelo, 2011, Do peso problems explain the returns to the carry trade?, Review of Financial Studies 24, 853-91.

Chernov, Mikhail, Jeremy Graveline, and Irina Zviadadze, 2012, Crash risk in currency returns, Working Paper, London Business School.

Domowitz, Ian, and Craig Hakkio, 1985, Conditional variance and the risk premium in the foreign exchange market, Journal of International Economics 19, 47-66.

Duffie, Darrell, and Rui Kan, 1996, A yield factor model of interest rates, Mathematical Finance 6, 379-406.

Engel, Charles, 1996, The forward discount anomaly and the risk premium: a survey of recent evidence, Journal of Empirical Finance 3, 123-191.

— , 2011, The real exchange rate, real interest rates, and the risk premium, Unpublished manuscript, University of Wisconsin.

Fama, Eugene F, 1984, Forward and spot exchange rates, Journal of Monetary Economics 14, 319-38. 
Hansen, Lars Peter, John C. Heaton, and Nan Li, 2008, Consumption strikes back? measuring long-run risk, Journal of Political Economy 116, 260-302.

Lustig, Hanno N., Nikolai L. Roussanov, and Adrien Verdelhan, 2011, Common risk factors in currency markets, Review of Financial Studies 24, 3731-3777.

Tryon, Ralph, 1979, Testing for rational expectations in foreign exchange markets, International Finance Discussion Paper \#139, Board of Govenors of the Federal Reserve System. 


\section{A Appendix: Proofs of Theorems}

\section{Proof of Theorem 1}

Note that, since $\left(\Sigma\left(z_{t}\right)-\Sigma\left(z_{t}^{*}\right)\right)$ is diagonal, positive definiteness requires $\sigma_{j}\left(z_{t}\right) \geq$ $\sigma_{j}\left(z_{t}^{*}\right)$, for every $j$, with at least one strict inequality (i.e. $\exists i$ such that $\sigma_{i}\left(z_{t}\right)>$ $\left.\sigma_{i}\left(z_{t}^{*}\right)\right)$. Now, when $\Omega=\Omega^{*}$, we have

$$
\operatorname{Var}_{t}\left(m_{t+1}\right)-\operatorname{Var}_{t}\left(m_{t+1}^{*}\right)=\lambda^{\top}\left(\Sigma\left(z_{t}\right)-\Sigma\left(z_{t}^{*}\right)\right) \lambda
$$

Therefore, by the definition of positive definiteness, we have

$$
\left(\Sigma\left(z_{t}\right)-\Sigma\left(z_{t}^{*}\right)\right) \text { is positive definite } \Leftrightarrow \operatorname{Var}_{t}\left(m_{t+1}\right)>\operatorname{Var}_{t}\left(m_{t+1}^{*}\right)
$$

whenever $\lambda \neq 0$. Similarly,

$$
\operatorname{Var}_{t}\left(i_{t+1}\right)-\operatorname{Var}_{t}\left(i_{t+1}^{*}\right)=\left(\gamma^{\top}-\frac{1}{2} \sum_{j=1}^{k} \lambda_{j}^{2} \beta_{j}^{\top}\right)\left(\Sigma\left(z_{t}\right)-\Sigma\left(z_{t}^{*}\right)\right)\left(\gamma^{\top}-\frac{1}{2} \sum_{j=1}^{k} \lambda_{j}^{2} \beta_{j}^{\top}\right)^{\top}
$$

Again, positive definiteness gives

$$
\left(\Sigma\left(z_{t}\right)-\Sigma\left(z_{t}^{*}\right)\right) \text { is positive definite } \Leftrightarrow \operatorname{Var}_{t}\left(i_{t+1}\right)>\operatorname{Var}_{t}\left(i_{t+1}^{*}\right)
$$

whenever $\left(\gamma^{\top}-\frac{1}{2} \sum_{j=1}^{k} \lambda_{j}^{2} \beta_{j}^{\top}\right) \neq 0$. Last, let $a \neq 0$ be any $k \times 1$ vector and note that the matrix $\left(\Sigma\left(z_{t}\right)-\Sigma\left(z_{t}^{*}\right)\right)$ is diagonal. Therefore,

$a^{\top}\left(\Sigma\left(z_{t}\right)-\Sigma\left(z_{t}^{*}\right)\right) a=\sum_{j=1}^{k} a_{j}^{2}\left(\sigma\left(z_{t}\right)-\sigma\left(z_{t}^{*}\right)\right)>0 \Leftrightarrow \sigma_{j}\left(z_{t}\right) \geq \sigma_{j}\left(z_{t}^{*}\right)$, for every $j$,

with at least one strict inequality associated with a non zero element of $a$.

\section{Proof of Theorem 2}

$$
\operatorname{Var}_{t}\left(m_{t+1}\right)-\operatorname{Var}_{t}\left(m_{t+1}^{*}\right)=\left(\lambda^{2}-\left(\lambda^{*}\right)^{2}\right)^{\top} \operatorname{diag}\left\{\Sigma\left(z_{t}\right)\right\}
$$

which, under the assumption that $\lambda$ and $\lambda^{*}$ can be ordered, is positive if and only if $\lambda^{2}>\left(\lambda^{*}\right)^{2}$, that is $|\lambda|>\left|\lambda^{*}\right|$. Moreover,

$$
\operatorname{Var}_{t}\left(i_{t+1}\right)-\operatorname{Var}_{t}\left(i_{t+1}^{*}\right)=\left(\left(\gamma^{\top}-\frac{1}{2} \sum_{j=1}^{k} \lambda_{j}^{2} \beta_{j}^{\top}\right)^{2}-\left(\gamma^{\top}-\frac{1}{2} \sum_{j=1}^{k}\left(\lambda_{j}^{*}\right)^{2} \beta_{j}^{\top}\right)^{2}\right)^{\top} \operatorname{diag}\left\{\Sigma\left(z_{t}\right)\right\}
$$

which, under the conditions that $\gamma=\gamma^{*}, \beta=\beta^{*}, \gamma^{\top}-\frac{1}{2} \sum_{j=1}^{k} \lambda_{j}^{2} \beta_{j}^{\top}<0$, and $\gamma^{\top}-\frac{1}{2} \sum_{j=1}^{k}\left(\lambda_{j}^{*}\right)^{2} \beta_{j}^{\top}<0$ is positive if only if $\lambda^{2}>\left(\lambda^{*}\right)^{2}$, that is $|\lambda|>\left|\lambda^{*}\right|$. 


\section{B Appendix: Data}

\section{B.1 Interest Rates}

Our main analysis is done with 3-month treasury bill yields for 114 countries from Global Financial Data (GFD) for the period 1950-2009 as it is the most comprehensive interest rate data available. As a robustness check, we also use eurocurrency interest rates from FT/ICAP through Datastream. FT/ICAP data consists of data for 27 mostly developed countries where for many of them data starts in 1975 .

Here we document the availability of various interest rates data from Datastream and why we thought FT/ICAP was the best interbank interest rate data available. In Datastream, the two sources for eurocurrency interest rates are FT/ICAP and ICAP while the British Bankers Association (BBA) gives the London interbank rates (LIBOR). ${ }^{5}$ Each have different set of countries and data years.

In 2006, Financial Times (FT) stopped providing euro currency rates to Datastream for the FT/ICAP series (for which Datastream mnemonic all starts with "EC") series. So Datastream continued these same series by splicing them with Intercapital (or ICAP, but formerly Garban Information Services (GS)) data so that starting in 2006, FT/ICAP and ICAP series are identical. For the countries for which GS is not available (e.g. Hong Kong, Singapore, South Africa), Tullett Prebon (TP) data was used instead. The TP data itself starts in 2006. The source column in Datastream's Navigator is not very informative. If the name of the series has FT/ICAP/TR, the source column will say "Thomson Reuters" but the source is really FT spliced with ICAP. If the name series has FT/TP, the source column appropriately says Tullett Prebon. The ones that have "dead" in the name have FT as the source and are dead series because neither ICAP nor TP has data on these countries. In Table 1, the countries of these dead series start with Greece and end with Thailand. For all the ICAP series (which start with "GS...."), the source column says "Thomson Reuters" but it is actually all ICAP.

A Datastream documentation file regarding this discontinuation of FT series gives alternative series that can be used instead. This list includes above mentioned ICAP, Tullett Prebon, BBA LIBORs, as well as "locally supplied" rates which are interbank rates from mainly national sources. These rates from national sources can be found under "National Interest Rates." The column "Alt IB" in Table 1 demonstrates the starting dates of the specific series that were listed in this document although there can be more than one interbank type rate under "National Interest Rates".

\footnotetext{
${ }^{5}$ There is also Tullett Prebon through Datastream that provides eurocurrency rates, but their data starts in 2006 only.
} 
Datastream has various interest rate data under "National Sources." In the future, our treasury bill yields data from GFD could be potential supplemented with the combination of Eurocurrency rates (mainly, FT/ICAP) and interbank rates from national sources. A Datastream documentation about risk free rates discusses this:

A risk free interest rate is the internal rate of return that can be obtained by investing in a financial instrument without (or very limited) credit risk. Normally this will relate to a short term investment in a financial instrument backed by the government. These money market securities bear no credit risk and have a limited re-investment risk, when the investment is rolled over for another short term period. In general we recommend the (annualised) yield on 3-month treasury bills, as the best instrument to use for any analysis involving risk free rates. However, for currencies where no liquid treasury bill market exists (or this market is subject to institutional distortions), interbank rates such as LIBOR or EURIBOR rates can be used. These do, however, bear a minimal credit risk inherent to the banks active in the market. Currencies with liquid repo-markets where the general collateral is a risk free long-term government bond, offer another alternative for an interest rate wich comes closest to 'risk-free', but are not available for as many currencies as interbank rates. A good example of this latter altenative is the Japanese 'Gensaki' market. The series we recommend for the main markets are detailed on the following table.

Column titled "Risk Free" in Table 1 demonstrates starting dates for the series specified in the document. Not shown in the table are Datastream's recommendations for risk free rates on Russia, China, Korea, Pakistan, Taiwan, Argentina, Brazil, Chile, Mexico and Venezuela also. Overall, this recommended list is not comprehensive (even few of the series above is suspended) and one would have to manually go through the various interest rates available for each country under "National Interest Rates" and pick the most relevant rate (most likely some interbank rate is the best) in order to supplement GFD data.

Lastly, for the seven (for BBA, it is six) euro legacy countries, since the introduction of the Euro in 1999, GS, EC, and BBA interest rates are identical across these countries. Obviously, we will not have the same problem with GFD treasury yields data. 


\begin{tabular}{|c|c|c|c|c|c|c|c|c|}
\hline \multirow[t]{2}{*}{ Market } & \multirow{2}{*}{$\begin{array}{c}\mathrm{FT} / \mathrm{ICAP} \\
\text { Start }\end{array}$} & \multirow{2}{*}{$\begin{array}{l}\text { ICAP } \\
\text { Start }\end{array}$} & \multirow{2}{*}{$\begin{array}{l}\text { BBA } \\
\text { Start }\end{array}$} & \multirow{2}{*}{$\begin{array}{l}\text { Alt IB } \\
\text { Start }\end{array}$} & \multirow{2}{*}{$\begin{array}{c}\text { "Risk Free" } \\
\text { Start }\end{array}$} & \multicolumn{3}{|c|}{ GFD } \\
\hline & & & & & & Start & End & nmiss \\
\hline Australia & 1997 & 1988 & 1986 & 1987 & 1977 & 1950 & 2009 & 3 \\
\hline Canada & 1975 & 1995 & 1990 & 1992 & 1981 & 1950 & 2009 & 1 \\
\hline Denmark & 1985 & 1995 & 2003 & 1989 & 1993 & 1976 & 2007 & 29 \\
\hline Hong Kong & 1997 & & & 1986 & & 1991 & 2009 & 1 \\
\hline Japan & 1978 & 1995 & 1986 & 1996 & & 1960 & 2009 & 1 \\
\hline New Zealand & 1997 & 1988 & 2003 & 1987 & 1989 & 1978 & 2009 & 3 \\
\hline Norway & 1997 & 1995 & & 1986 & 1986 & 1984 & 2009 & 1 \\
\hline Singapore & 1988 & & & 1987 & 1989 & 1987 & 2009 & 1 \\
\hline South Africa & 1997 & & & 2000 & & 1950 & 2009 & 1 \\
\hline Sweden & 1997 & 1995 & 2006 & 1993 & 1994 & 1955 & 2009 & 1 \\
\hline Switzerland & 1975 & 1995 & 1986 & 1974 & 1950 & 1980 & 2009 & 3 \\
\hline United Kingdom & 1975 & 1995 & 1986 & 1975 & 1972 & 1950 & 2009 & 1 \\
\hline United States & 1975 & 1995 & 1986 & 1971 & 1955 & 1950 & 2009 & 1 \\
\hline Other Western European & 1999 & 1999 & 1998 & 1999 & 1999 & 1984 & 2009 & 2 \\
\hline Belgium & 1978 & 1995 & & & & 1950 & 2009 & 2 \\
\hline France & 1975 & 1995 & 1989 & & & 1950 & 2009 & 61 \\
\hline Germany & 1975 & 1995 & 1986 & & & 1953 & 2009 & 2 \\
\hline Italy & 1978 & 1995 & 1990 & & & 1950 & 2009 & 2 \\
\hline Netherlands & 1975 & 1995 & 1991 & & & 1950 & 2009 & 2 \\
\hline Portugal & 1992 & 1995 & 1994 & & & 1985 & 2009 & 2 \\
\hline Spain & 1992 & 1996 & 1990 & & & 1982 & 2009 & 2 \\
\hline Greece & 1999 & & & & & 1980 & 2009 & 2 \\
\hline India & 1999 & & & 1999 & 1994 & 1993 & 2009 & 1 \\
\hline Indonesia & 1997 & & & 2001 & 1985 & 2000 & 2003 & 72 \\
\hline Malaysia & 1997 & & & 1994 & 1998 & 1961 & 2009 & 1 \\
\hline Philippines & 1999 & & & & & 1976 & 2009 & 3 \\
\hline Thailand & 1997 & & & 2005 & 1995 & 1977 & 2009 & 88 \\
\hline Total & 27 & 18 & 16 & 18 & 15 & & 27 & \\
\hline
\end{tabular}

Table 1: This table compares various interest rates data available from Datastream (the first five columns) with GFD data. "nmiss" stands for the number of missing months 


\begin{tabular}{|c|c|c|c|c|c|c|c|}
\hline Market & Start & End & nmiss & Market & Start & End & nmiss \\
\hline ALBANIA & 1994 & 2009 & 4 & KOREA, REPUBLIC OF & 1987 & 2009 & 2 \\
\hline ALGERIA & 1998 & 2009 & 5 & KUWAIT & 1979 & 2005 & 59 \\
\hline ANGOLA & 2000 & 2009 & 3 & KYRGYZSTAN & 1994 & 2009 & 3 \\
\hline ARGENTINA & 2002 & 2009 & 16 & LATVIA & 1994 & 2008 & 16 \\
\hline ARMENIA & 1995 & 2009 & 3 & LEBANON & 1977 & 2009 & 4 \\
\hline AUSTRIA & 1960 & 1990 & 228 & LITHUANIA & 1994 & 2009 & 4 \\
\hline AZERBAIJAN & 1997 & 2009 & 9 & MACEDONIA & 1997 & 2009 & 3 \\
\hline BAHAMAS & 1971 & 2009 & 3 & MADAGASCAR & 2000 & 2009 & 3 \\
\hline BAHRAIN & 1987 & 2009 & 3 & MALTA & 1987 & 2009 & 3 \\
\hline BANGLADESH & 1984 & 2009 & 29 & MAURITIUS & 1996 & 2009 & 3 \\
\hline BARBADOS & 1966 & 2009 & 5 & MEXICO & 1978 & 2009 & 6 \\
\hline BELIZE & 1978 & 2009 & 4 & MOLDOVA, REPUBLIC OF & 1995 & 2009 & 3 \\
\hline BOLIVIA & 1994 & 2009 & 6 & MONGOLIA & 2006 & 2008 & 20 \\
\hline BOTSWANA & 1996 & 2009 & 3 & MONTENEGRO & 2004 & 2009 & 3 \\
\hline BRAZIL & 1965 & 2009 & 62 & MOROCCO & 2008 & 2009 & 4 \\
\hline BULGARIA & 1992 & 2008 & 23 & MOZAMBIQUE & 2000 & 2009 & 4 \\
\hline BURUNDI & 2001 & 2009 & 29 & NAMIBIA & 1991 & 2009 & 8 \\
\hline CAPE VERDE & 1998 & 2009 & 3 & NEPAL & 1981 & 2008 & 17 \\
\hline CENTRAL AFRICAN REPUBLIC & 1996 & 2004 & 139 & NICARAGUA & 2003 & 2007 & 24 \\
\hline CHILE & 1997 & 2009 & 2 & NIGERIA & 1970 & 2009 & 229 \\
\hline CHINA & 2002 & 2009 & 1 & PAKISTAN & 1991 & 2009 & 1 \\
\hline COLOMBIA & 1998 & 2009 & 2 & POLAND & 1991 & 2009 & 1 \\
\hline COSTA RICA & 1996 & 2009 & 3 & ROMANIA & 1994 & 2005 & 51 \\
\hline CROATIA & 2000 & 2009 & 3 & RUSSIAN FEDERATION & 1994 & 2009 & 18 \\
\hline CYPRUS & 1975 & 2008 & 21 & RWANDA & 1999 & 2009 & 5 \\
\hline CZECH REPUBLIC & 1993 & 2009 & 5 & SAUDI ARABIA & 1991 & 2008 & 12 \\
\hline EGYPT & 1991 & 2009 & 1 & SERBIA & 1997 & 2009 & 34 \\
\hline EL SALVADOR & 2001 & 2005 & 51 & SIERRA LEONE & 1965 & 2008 & 12 \\
\hline ETHIOPIA & 1985 & 2008 & 12 & SLOVAK REPUBLIC & 1993 & 2007 & 24 \\
\hline FIJI & 1975 & 2009 & 4 & SLOVENIA & 1998 & 2009 & 5 \\
\hline GEORGIA & 2001 & 2005 & 54 & SRI LANKA & 1981 & 2009 & 1 \\
\hline GHANA & 1978 & 2009 & 9 & SWAZILAND & 1981 & 2006 & 45 \\
\hline GUYANA & 1972 & 2009 & 6 & TAIWAN & 1974 & 2009 & 3 \\
\hline HAITI & 1996 & 2009 & 2 & TANZANIA, UNITED REPUBLIC OF & 1993 & 2009 & 5 \\
\hline HONDURAS & 1998 & 2000 & 108 & TRINIDAD AND TOBAGO & 1964 & 2009 & 7 \\
\hline HUNGARY & 1988 & 2009 & 3 & TUNISIA & 1990 & 2009 & 2 \\
\hline ICELAND & 1987 & 2009 & 2 & TURKEY & 1985 & 2009 & 3 \\
\hline IRAQ & 2004 & 2009 & 3 & UGANDA & 1980 & 2009 & 3 \\
\hline IRELAND & 1969 & 2009 & 2 & URUGUAY & 1992 & 2009 & 49 \\
\hline ISRAEL & 1992 & 2009 & 2 & VENEZUELA & 1996 & 2003 & 72 \\
\hline JAMAICA & 1953 & 2009 & 3 & VIET NAM & 1997 & 2009 & 9 \\
\hline JORDAN & 2000 & 2009 & 36 & ZAMBIA & 1978 & 2009 & 3 \\
\hline KAZAKHSTAN & 1994 & 2009 & 2 & ZIMBABWE & 1962 & 2009 & 11 \\
\hline KENYA & 1972 & 2009 & 8 & & & & \\
\hline
\end{tabular}

Table 2: The remaining 87 GFD interest rates (mainly treasury yields). "nmiss" stands for number of missing months. 


\section{B.2 Exchange Rate Data}

Our main exchange rate data is from GFD for 172 countries for the period 19502009. This dataset is most comprehensive compared to three different data sources of forward and spot exchange rates available through Datastream: Barclays Bank PLC (BBI), Tenfore, and WM/Reuters (WMR). For each of these sources, full sample of countries and data years vary and are a lot more limited compared to GFD as shown in the table belows.

\begin{tabular}{|c|c|c|c|c|c|c|c|}
\hline & $\mathrm{WM} / \mathrm{R}$ & Tenfore & Barclays & & WM/R & Tenfore & Barclays \\
\hline Argentine Peso & 2004 & & & Latvian Lat & 2004 & & \\
\hline Australian Dollar & 1996 & 1990 & 1984 & Lithuanian Lita & 2004 & & \\
\hline Austrian Schilling & 1996 & & & Malaysian Ringgit & 1996 & & \\
\hline Belgian Franc & 1996 & & & Maltese Lira & 2004 & & \\
\hline Brazilian Real & 2004 & & & Mexican Peso & 1996 & & \\
\hline Bulgarian Lev & 2004 & & & Moroccan Dirham & 2004 & & \\
\hline Canadian Dollar & 1996 & 1990 & 1984 & New Zealand Dollar & 1996 & 1990 & 1984 \\
\hline Chilean Peso & 2004 & & & Norwegian Krone & 1996 & 1990 & 1984 \\
\hline Chinese Yuan Renminbi & 2002 & & & Omani Rial & 2004 & & \\
\hline Colombian Peso & 2004 & & & Pakistani Rupee & 2004 & & \\
\hline Croatian Kuna & 2004 & & & Peruvian Nuevo Sol & 2004 & & \\
\hline Cyprian Pound & 2004 & & & Philippine Peso & 1996 & 2006 & \\
\hline Czech Koruna & 1996 & 1996 & & Polish Zloty & 2002 & 1996 & \\
\hline Danish Krone & 1996 & 1990 & 1984 & Portuguese Escudo & 1996 & & \\
\hline Dutch Guilder & 1996 & & & Qatari Riyal & 2004 & & \\
\hline Egyptian Pound & 2004 & & & Romanian Leu & 2004 & 2008 & \\
\hline Estonian Kroon & 2004 & & & Russian Federation Rouble & 2004 & & \\
\hline Euro & 1998 & 1990 & 1999 & Saudi Arabian Riyal & 1996 & 1990 & \\
\hline Finnish Markka & 1996 & & & Singaporean Dollar & 1996 & 1990 & 1984 \\
\hline French Franc & 1996 & & & Slovak Koruna & 2002 & & \\
\hline German Mark & 1996 & & & Slovenian Tolar & 2004 & & \\
\hline Greek Drachma & 1996 & & & South African Rand & 1996 & 1990 & 1983 \\
\hline Hong Kong Dollar & 1996 & 1990 & 1983 & Spanish Peseta & 1996 & & \\
\hline Hungarian Forint & 1997 & & & Swedish Krona & 1996 & 1990 & 1984 \\
\hline Icelandic Krona & 2004 & 2006 & & Swiss Franc & 1996 & 1990 & 1983 \\
\hline Indian Rupee & 1997 & & & Taiwanese Dollar & 1996 & & \\
\hline Indonesian Rupiah & 1996 & & & Thai Baht & 1996 & 1995 & \\
\hline Irish Punt or Pound & 1996 & & & Tunisian Dinar & 2004 & & \\
\hline Israeli Sheqel & 2004 & 2006 & & Turkish Lira & 1996 & 2006 & \\
\hline Italian Lira & 1996 & & & Ukrainian Hryvnia & 2004 & 2008 & \\
\hline Japanese Yen & 1996 & 1990 & 1983 & United Arab Emirates Dirham & 1996 & 1995 & \\
\hline Jordanian Dinar & 2004 & & & United Kingdom Pound & 1996 & 1990 & 1983 \\
\hline Kazakh Tenge & 2004 & & & Venezuelan Bolivar & 2004 & & \\
\hline Kenyan Shilling & 2004 & & & & & & \\
\hline Korean Won & 2002 & & & Total & 69 & 25 & 13 \\
\hline Kuwaiti Dinar & 1996 & 1990 & & & & & \\
\hline
\end{tabular}

Table 3: Exchange rate data sources from Datastream

\section{B.3 GARCH Model}

Interest rates, $r_{t}$, are $\mathrm{AR}(\mathrm{p})$ process:

$$
r_{t}=c+\beta_{1} r_{t-1}+\ldots \beta_{p} r_{t-p}+u_{t}
$$

where $u_{t}$ is $G A R C H(r, m)$ :

$$
u_{t} \sim N\left(0, \sigma_{t}^{2}\right)
$$




$$
\sigma_{t}^{2}=\kappa+\sum_{i=1}^{r} \delta_{i} \sigma_{t-i}^{2}+\sum_{i=1}^{m} \alpha_{i} u_{t-i}^{2}
$$

For all countries, we first fit $\mathrm{AR}(5)$ to the interest rates, and fit the residuals to $\operatorname{GARCH}(1,1){ }^{6}$

\footnotetext{
${ }^{6}$ In the future, we will update our procedure to estimate the parameters of AR and GARCH processes at the same time.
} 


\begin{tabular}{|c|c|c|c|c|c|c|c|c|c|}
\hline & all & 1975 & 1987 & 1995 & & all & 1975 & 1987 & 1995 \\
\hline ALB & 1 & 0 & 0 & 1 & KOR & 1 & 0 & 1 & 1 \\
\hline DZA & 1 & 0 & 0 & 0 & KWT & 1 & 0 & 1 & 1 \\
\hline AGO & 1 & 0 & 0 & 0 & KGZ & 1 & 0 & 0 & 1 \\
\hline ARG & 1 & 0 & 0 & 0 & LVA & 1 & 0 & 0 & 1 \\
\hline ARM & 1 & 0 & 0 & 0 & LBN & 1 & 0 & 1 & 1 \\
\hline AUS & 1 & 1 & 1 & 1 & LTU & 1 & 0 & 0 & 1 \\
\hline AUT & 1 & 1 & 1 & 0 & MKD & 1 & 0 & 0 & 0 \\
\hline AZE & 1 & 0 & 0 & 0 & MDG & 1 & 0 & 0 & 0 \\
\hline BHS & 1 & 1 & 1 & 1 & MYS & 1 & 1 & 1 & 1 \\
\hline BHR & 1 & 0 & 0 & 1 & MLT & 1 & 0 & 0 & 1 \\
\hline BGD & 1 & 0 & 1 & 1 & MUS & 1 & 0 & 0 & 0 \\
\hline BRB & 1 & 1 & 1 & 1 & MEX & 1 & 0 & 1 & 1 \\
\hline BEL & 1 & 1 & 1 & 1 & MDA & 1 & 0 & 0 & 0 \\
\hline BLZ & 1 & 0 & 1 & 1 & MNG & 1 & 0 & 0 & 0 \\
\hline BOL & 1 & 0 & 0 & 1 & $\mathrm{MNE}$ & 1 & 0 & 0 & 0 \\
\hline BWA & 1 & 0 & 0 & 0 & MAR & 1 & 0 & 0 & 0 \\
\hline BRA & 1 & 1 & 1 & 1 & $\mathrm{MOZ}$ & 1 & 0 & 0 & 0 \\
\hline BGR & 1 & 0 & 0 & 1 & NAM & 1 & 0 & 0 & 1 \\
\hline BDI & 1 & 0 & 0 & 0 & NPL & 1 & 0 & 1 & 1 \\
\hline CAN & 1 & 1 & 1 & 1 & NLD & 1 & 1 & 1 & 1 \\
\hline $\mathrm{CPV}$ & 1 & 0 & 0 & 0 & NZL & 1 & 0 & 1 & 1 \\
\hline CAF & 1 & 0 & 0 & 0 & NIC & 1 & 0 & 0 & 0 \\
\hline CHL & 1 & 0 & 0 & 0 & NGA & 1 & 0 & 0 & 1 \\
\hline CHN & 1 & 0 & 0 & 0 & NOR & 1 & 0 & 1 & 1 \\
\hline COL & 1 & 0 & 0 & 0 & PAK & 1 & 0 & 0 & 1 \\
\hline CRI & 1 & 0 & 0 & 0 & PHL & 1 & 0 & 1 & 1 \\
\hline HRV & 1 & 0 & 0 & 0 & POL & 1 & 0 & 0 & 1 \\
\hline CYP & 1 & 1 & 1 & 1 & PRT & 1 & 0 & 1 & 1 \\
\hline CZE & 1 & 0 & 0 & 1 & $\mathrm{ROU}$ & 1 & 0 & 0 & 1 \\
\hline DNK & 1 & 0 & 1 & 1 & RUS & 1 & 0 & 0 & 1 \\
\hline EGY & 1 & 0 & 0 & 1 & RWA & 1 & 0 & 0 & 0 \\
\hline SLV & 1 & 0 & 0 & 0 & SAU & 1 & 0 & 0 & 1 \\
\hline ETH & 1 & 0 & 1 & 1 & SRB & 1 & 0 & 0 & 0 \\
\hline EUR & 1 & 0 & 1 & 1 & SLE & 1 & 1 & 1 & 1 \\
\hline FJI & 1 & 1 & 1 & 1 & SGP & 1 & 0 & 0 & 1 \\
\hline FRA & 1 & 1 & 1 & 1 & SVK & 1 & 0 & 0 & 1 \\
\hline GEO & 1 & 0 & 0 & 0 & SVN & 1 & 0 & 0 & 0 \\
\hline DEU & 1 & 1 & 1 & 1 & ZAF & 1 & 1 & 1 & 1 \\
\hline GHA & 1 & 0 & 1 & 1 & ESP & 1 & 0 & 1 & 1 \\
\hline GRC & 1 & 0 & 1 & 1 & LKA & 1 & 0 & 1 & 1 \\
\hline GUY & 1 & 1 & 1 & 1 & SWZ & 1 & 0 & 1 & 1 \\
\hline HTI & 1 & 0 & 0 & 0 & SWE & 1 & 1 & 1 & 1 \\
\hline HND & 1 & 0 & 0 & 0 & CHE & 1 & 0 & 1 & 1 \\
\hline HKG & 1 & 0 & 0 & 1 & TWN & 1 & 1 & 1 & 1 \\
\hline HUN & 1 & 0 & 0 & 1 & TZA & 1 & 0 & 0 & 1 \\
\hline ISL & 1 & 0 & 0 & 1 & THA & 1 & 0 & 1 & 0 \\
\hline IND & 1 & 0 & 0 & 1 & TTO & 1 & 1 & 1 & 1 \\
\hline IDN & 1 & 0 & 0 & 0 & TUN & 1 & 0 & 0 & 1 \\
\hline IRQ & 1 & 0 & 0 & 0 & TUR & 1 & 0 & 1 & 1 \\
\hline IRL & 1 & 1 & 1 & 1 & UGA & 1 & 0 & 1 & 1 \\
\hline ISR & 1 & 0 & 0 & 1 & GBR & 1 & 1 & 1 & 1 \\
\hline ITA & 1 & 1 & 1 & 1 & USA & 1 & 1 & 1 & 1 \\
\hline JAM & 1 & 1 & 1 & 1 & URY & 1 & 0 & 0 & 1 \\
\hline JPN & 1 & 1 & 1 & 1 & VEN & 1 & 0 & 0 & 0 \\
\hline JOR & 1 & 0 & 0 & 0 & VNM & 1 & 0 & 0 & 0 \\
\hline KAZ & 1 & 0 & 0 & 1 & ZMB & 1 & 0 & 1 & 1 \\
\hline KEN & 1 & 1 & 1 & 1 & ZWE & 1 & 1 & 1 & 1 \\
\hline
\end{tabular}

Table 4: The countries that get included in the various data period subsamples. One means it is included, zero otherwise. For example, countries with ones in the column for 1975 means these were the countries that had non-missing interest rate data in Jan 1975 


\begin{tabular}{|c|c|c|c|c|c|c|c|c|c|}
\hline & \multicolumn{4}{|c|}{ rate } & \multicolumn{4}{|c|}{ vol } & \multirow[b]{2}{*}{ nobs } \\
\hline & $\min$ & $\max$ & mean & std & $\min$ & $\max$ & mean & std & \\
\hline ALB & 5.05 & 38.23 & 12.32 & 8.32 & 0.19 & 4.34 & 0.70 & 0.68 & 183 \\
\hline DZA & 0.09 & 10.13 & 3.72 & 3.75 & 0.42 & 1.70 & 0.57 & 0.26 & 135 \\
\hline $\mathrm{AGO}$ & 2.80 & 134.00 & 55.13 & 47.86 & 1.04 & 25.02 & 6.10 & 5.76 & 110 \\
\hline $\mathrm{ARG}$ & 1.10 & 59.77 & 10.02 & 8.81 & - & - & - & - & 22 \\
\hline ARM & 3.24 & 80.42 & 22.85 & 20.02 & 0.42 & 17.20 & 3.57 & 3.85 & 170 \\
\hline AUS & 0.75 & 19.40 & 6.30 & 4.19 & 0.08 & 2.72 & 0.34 & 0.41 & 717 \\
\hline AUT & 3.61 & 10.38 & 6.63 & 1.66 & 0.10 & 0.81 & 0.14 & 0.06 & 373 \\
\hline AZE & 3.92 & 22.10 & 11.76 & 4.37 & 0.97 & 3.03 & 1.54 & 0.46 & 144 \\
\hline BHS & 0.06 & 9.90 & 4.44 & 2.56 & 0.28 & 1.73 & 0.55 & 0.26 & 463 \\
\hline BHR & 0.69 & 9.98 & 4.73 & 2.18 & 0.14 & 0.52 & 0.24 & 0.08 & 269 \\
\hline BGD & 1.86 & 11.50 & 8.03 & 1.80 & 0.10 & 1.07 & 0.19 & 0.17 & 205 \\
\hline BRB & 0.24 & 16.02 & 5.88 & 2.42 & 0.17 & 1.75 & 0.37 & 0.25 & 513 \\
\hline BEL & 0.34 & 14.03 & 6.18 & 2.83 & 0.12 & 1.67 & 0.25 & 0.16 & 718 \\
\hline BLZ & 3.22 & 14.46 & 6.38 & 3.06 & 0.03 & 2.27 & 0.18 & 0.32 & 370 \\
\hline BOL & 0.75 & 26.60 & 11.69 & 5.69 & 0.85 & 3.87 & 1.18 & 0.45 & 187 \\
\hline BWA & 8.16 & 14.31 & 12.39 & 0.98 & 0.19 & 0.79 & 0.28 & 0.11 & 165 \\
\hline BRA & 8.65 & 933.60 & 68.71 & 115.38 & 1.42 & 185.95 & 10.15 & 21.50 & 295 \\
\hline BGR & 2.12 & 1232.75 & 48.10 & 131.98 & 6.08 & 1006.04 & 24.15 & 82.10 & 194 \\
\hline BDI & 6.41 & 19.84 & 9.85 & 3.05 & 0.11 & 1.17 & 0.47 & 0.30 & 66 \\
\hline $\mathrm{CAN}$ & 0.20 & 20.90 & 5.69 & 3.73 & 0.11 & 1.77 & 0.38 & 0.28 & 719 \\
\hline CPV & 2.00 & 11.08 & 5.69 & 2.29 & 0.14 & 1.51 & 0.43 & 0.32 & 142 \\
\hline $\mathrm{CAF}$ & 2.08 & 3.73 & 2.63 & 0.57 & - & - & - & - & 12 \\
\hline CHL & 0.46 & 19.17 & 6.73 & 4.49 & 0.24 & 4.55 & 0.86 & 0.77 & 149 \\
\hline $\mathrm{CHN}$ & 1.21 & 4.50 & 2.63 & 0.91 & 0.31 & 1.28 & 0.39 & 0.16 & 96 \\
\hline COL & 4.35 & 52.64 & 13.75 & 9.33 & 0.26 & 6.38 & 1.33 & 1.55 & 108 \\
\hline CRI & 3.33 & 24.50 & 15.44 & 4.90 & 1.10 & 5.50 & 1.37 & 0.56 & 163 \\
\hline HRV & 1.90 & 7.60 & 4.27 & 1.62 & 0.31 & 1.03 & 0.50 & 0.17 & 107 \\
\hline CYP & 2.46 & 6.23 & 5.30 & 0.84 & 0.02 & 1.04 & 0.07 & 0.11 & 400 \\
\hline CZE & 1.66 & 15.54 & 5.75 & 3.71 & 0.16 & 1.52 & 0.31 & 0.22 & 193 \\
\hline DNK & 2.00 & 20.70 & 9.94 & 5.90 & 0.40 & 4.62 & 0.60 & 0.48 & 380 \\
\hline EGY & 5.26 & 19.40 & 10.53 & 3.26 & 0.03 & 3.79 & 0.44 & 0.53 & 228 \\
\hline SLV & 2.82 & 6.99 & 3.77 & 0.95 & - & - & - & - & 56 \\
\hline ETH & 0.04 & 12.00 & 3.83 & 3.71 & 0.02 & & 0.35 & 0.71 & 284 \\
\hline EUR & 0.34 & 11.75 & 5.81 & 3.03 & 0.07 & 1.10 & 0.27 & 0.19 & 311 \\
\hline FJI & 0.07 & 18.65 & 4.06 & 2.74 & 0.05 & 5.47 & 0.67 & 0.81 & 417 \\
\hline FRA & 0.37 & 18.92 & 6.31 & 3.71 & 0.08 & 1.77 & 0.36 & 0.26 & 600 \\
\hline GEO & 9.95 & 58.44 & 31.79 & 14.05 & - & - & - & - & 55 \\
\hline DEU & 0.34 & 12.05 & 4.39 & 2.02 & 0.15 & 1.55 & 0.32 & 0.17 & 683 \\
\hline GHA & 9.38 & 46.75 & 22.22 & 10.27 & 0.53 & 7.69 & 1.05 & 0.93 & 376 \\
\hline GRC & 0.72 & 25.50 & 11.44 & 6.13 & 0.18 & 6.55 & 0.44 & 0.60 & 359 \\
\hline GUY & 2.84 & 33.75 & 10.67 & 6.91 & 0.04 & 12.99 & 0.44 & 0.95 & 420 \\
\hline HTI & 4.00 & 27.83 & 16.42 & 7.36 & 1.53 & 6.26 & 2.07 & 0.90 & 157 \\
\hline HND & 13.97 & 18.00 & 14.71 & 1.31 & - & - & - & - & 26 \\
\hline HKG & -0.08 & 12.24 & 3.53 & 2.27 & 0.27 & 3.14 & 0.56 & 0.45 & 223 \\
\hline HUN & 5.55 & 35.30 & 16.81 & 8.95 & 0.52 & 2.90 & 1.01 & 0.47 & 251 \\
\hline ISL & 4.44 & 34.30 & 11.46 & 6.53 & 0.27 & 5.01 & 1.01 & 0.93 & 270 \\
\hline IND & 3.39 & 14.00 & 8.19 & 2.53 & 0.57 & 1.71 & 0.81 & 0.25 & 204 \\
\hline IDN & 3.50 & 14.50 & 8.97 & 2.42 & - & - & - & - & 48 \\
\hline IRQ & 1.20 & 22.00 & 11.63 & 6.32 & 2.16 & 3.91 & 2.56 & 0.46 & 70 \\
\hline IRL & 0.31 & 39.94 & 8.07 & 4.60 & 0.32 & 15.05 & 0.88 & 1.27 & 480 \\
\hline ISR & 0.29 & 17.96 & 8.73 & 4.54 & 0.23 & 1.58 & 0.58 & 0.28 & 215 \\
\hline ITA & 0.31 & 22.08 & 7.48 & 5.19 & 0.05 & 2.44 & 0.43 & 0.42 & 718 \\
\hline JAM & 1.75 & 51.98 & 12.81 & 10.16 & 0.23 & 6.48 & 0.97 & 1.11 & 682 \\
\hline JPN & 0.00 & 8.27 & 3.78 & 2.50 & 0.03 & 0.64 & 0.14 & 0.13 & 600 \\
\hline JOR & 2.05 & 6.88 & 4.93 & 1.71 & 0.23 & 0.80 & 0.35 & 0.12 & 71 \\
\hline KAZ & 2.09 & 318.78 & 28.70 & 60.71 & 0.17 & 29.70 & 2.48 & 4.87 & 188 \\
\hline KEN & 0.11 & 70.64 & 11.98 & 9.39 & 0.43 & 8.72 & 1.39 & 1.36 & 405 \\
\hline
\end{tabular}

Table 5: Descriptive statistics of GFD interest rates and the computed volatility. The volatility is based on the entire interest rate data available for that country. The last column (nobs) shows the number of consecutive months with non-missing data. 


\begin{tabular}{|c|c|c|c|c|c|c|c|c|c|}
\hline & \multicolumn{4}{|c|}{ rate } & \multicolumn{4}{|c|}{ volatility } & \multirow[b]{2}{*}{ nobs } \\
\hline & $\min$ & $\max$ & mean & std & $\min$ & $\max$ & mean & std & \\
\hline KOR & 2.48 & 19.20 & 9.78 & 4.78 & 0.21 & 1.56 & 0.61 & 0.33 & 275 \\
\hline KWT & 0.60 & 8.87 & 6.12 & 1.78 & 0.03 & 1.19 & 0.18 & 0.19 & 311 \\
\hline KGZ & 3.47 & 216.50 & 28.94 & 36.62 & 1.79 & 33.82 & 6.19 & 5.79 & 190 \\
\hline LVA & 2.30 & 33.98 & 8.11 & 8.06 & 0.50 & 4.67 & 0.94 & 0.74 & 173 \\
\hline $\mathrm{LBN}$ & 2.54 & 34.18 & 12.34 & 5.72 & 0.12 & 7.86 & 0.66 & 0.95 & 382 \\
\hline LTU & 1.96 & 37.00 & 8.81 & 8.46 & 0.21 & 1.09 & 0.42 & 0.25 & 115 \\
\hline MKD & 4.66 & 18.00 & 8.63 & 2.72 & 0.33 & 2.47 & 0.67 & 0.43 & 143 \\
\hline MDG & 3.92 & 24.04 & 12.49 & 5.01 & 0.53 & 3.64 & 0.85 & 0.57 & 111 \\
\hline MYS & 1.82 & 9.98 & 4.39 & 1.35 & 0.04 & 1.48 & 0.18 & 0.18 & 588 \\
\hline MLT & 1.46 & 5.49 & 4.26 & 0.81 & 0.04 & 0.88 & 0.10 & 0.11 & 264 \\
\hline MUS & 3.68 & 12.91 & 8.50 & 2.32 & 0.26 & 1.71 & 0.51 & 0.24 & 155 \\
\hline MEX & 4.56 & 153.91 & 29.03 & 25.98 & 0.46 & 13.42 & 2.39 & 2.35 & 251 \\
\hline MDA & 1.21 & 74.30 & 19.73 & 13.39 & 1.99 & 6.98 & 2.94 & 1.25 & 176 \\
\hline MNG & 5.56 & 7.91 & 6.93 & 0.77 & - & - & - & - & 27 \\
\hline MNE & 0.45 & 10.80 & 2.65 & 3.59 & 0.17 & 2.65 & 0.65 & 0.58 & 64 \\
\hline MAR & 3.24 & 3.70 & 3.46 & 0.16 & - & - & - & - & 21 \\
\hline MOZ & 7.15 & 31.65 & 16.70 & 6.53 & 1.53 & 8.99 & 1.93 & 0.93 & 117 \\
\hline NAM & 6.66 & 21.68 & 11.60 & 3.22 & 0.35 & 1.79 & 0.54 & 0.23 & 217 \\
\hline NPL & 0.62 & 12.88 & 5.48 & 2.62 & 0.03 & 1.76 & 0.50 & 0.40 & 332 \\
\hline NLD & 0.23 & 13.80 & 4.36 & 2.63 & 0.10 & 1.61 & 0.34 & 0.25 & 718 \\
\hline NZL & 2.62 & 27.20 & 9.51 & 4.74 & 0.11 & 3.92 & 0.63 & 0.67 & 380 \\
\hline NIC & 1.02 & 6.50 & 3.91 & 1.83 & - & - & - & - & 55 \\
\hline NGA & 2.00 & 27.50 & 12.95 & 5.42 & 0.00 & 8.69 & 0.79 & 0.94 & 220 \\
\hline NOR & 0.10 & 15.75 & 7.09 & 3.85 & 0.30 & 9.93 & 0.70 & 0.99 & 312 \\
\hline PAK & 1.21 & 17.42 & 10.05 & 3.80 & 0.21 & 1.79 & 0.59 & 0.30 & 226 \\
\hline PHL & 2.92 & 43.39 & 12.50 & 6.57 & 0.26 & 5.91 & 1.05 & 0.96 & 399 \\
\hline POL & 3.90 & 49.02 & 16.57 & 12.10 & 0.16 & 7.64 & 1.06 & 1.31 & 224 \\
\hline PRT & 0.31 & 22.19 & 7.54 & 5.07 & 0.15 & 1.16 & 0.38 & 0.22 & 292 \\
\hline $\mathrm{ROU}$ & 7.82 & 179.94 & 48.65 & 32.35 & 5.11 & 39.99 & 9.25 & 6.77 & 140 \\
\hline RUS & 0.26 & 355.80 & 33.46 & 59.80 & 1.53 & 3.00 & 1.70 & 0.21 & 114 \\
\hline RWA & 5.24 & 12.85 & 9.57 & 1.80 & 0.24 & 2.21 & 0.57 & 0.35 & 128 \\
\hline $\mathrm{SAU}$ & 1.12 & 7.16 & 4.41 & 1.65 & 0.16 & 0.75 & 0.29 & 0.12 & 207 \\
\hline SRB & 4.20 & 99.25 & 17.52 & 12.85 & 0.78 & 5.92 & 1.57 & 0.97 & 108 \\
\hline SLE & 3.80 & 95.20 & 16.56 & 14.98 & 0.34 & 23.59 & 1.46 & 2.26 & 519 \\
\hline SGP & 0.20 & 4.90 & 1.90 & 1.17 & 0.16 & 1.30 & 0.46 & 0.22 & 265 \\
\hline SVK & 1.95 & 26.00 & 9.36 & 5.90 & 0.15 & 5.81 & 1.17 & 1.12 & 180 \\
\hline SVN & 0.55 & 12.70 & 6.37 & 3.30 & 0.08 & 1.47 & 0.47 & 0.27 & 96 \\
\hline $\mathrm{ZAF}$ & 1.00 & 22.15 & 8.06 & 5.11 & 0.08 & 1.91 & 0.34 & 0.31 & 719 \\
\hline ESP & 0.31 & 15.27 & 7.39 & 4.40 & 0.15 & 1.45 & 0.36 & 0.24 & 329 \\
\hline LKA & 6.54 & 21.30 & 13.08 & 3.20 & 0.40 & 3.07 & 0.94 & 0.49 & 345 \\
\hline SWZ & 4.93 & 19.50 & 10.83 & 3.27 & 0.53 & 1.90 & 0.77 & 0.26 & 293 \\
\hline SWE & 0.13 & 18.00 & 6.46 & 3.78 & 0.25 & 3.70 & 0.53 & 0.39 & 660 \\
\hline CHE & 0.00 & 9.30 & 3.30 & 2.43 & 0.09 & 1.05 & 0.36 & 0.22 & 358 \\
\hline TWN & 0.17 & 14.99 & 5.46 & 3.18 & 0.08 & 2.52 & 0.27 & 0.32 & 428 \\
\hline TZA & 2.60 & 62.30 & 13.25 & 11.01 & 0.69 & 11.80 & 2.36 & 1.90 & 189 \\
\hline THA & 1.02 & 19.32 & 6.19 & 4.12 & 0.10 & 3.28 & 0.40 & 0.59 & 156 \\
\hline TTO & 2.30 & 12.11 & 5.92 & 2.52 & 0.04 & 1.44 & 0.18 & 0.22 & 535 \\
\hline TUN & 4.02 & 11.62 & 7.38 & 2.17 & 0.45 & 0.93 & 0.46 & 0.05 & 239 \\
\hline TUR & 7.92 & 159.44 & 56.71 & 32.63 & 1.07 & 25.30 & 7.21 & 5.85 & 170 \\
\hline UGA & 2.97 & 43.50 & 16.74 & 11.90 & 0.86 & 10.88 & 1.73 & 1.34 & 358 \\
\hline GBR & 0.42 & 16.27 & 6.77 & 3.58 & 0.18 & 1.29 & 0.48 & 0.28 & 719 \\
\hline USA & 0.01 & 15.52 & 4.77 & 2.87 & 0.13 & 1.97 & 0.37 & 0.29 & 719 \\
\hline URY & 2.26 & 146.47 & 26.98 & 25.14 & 1.12 & 9.09 & 2.96 & 2.20 & 87 \\
\hline VEN & 8.89 & 57.05 & 21.98 & 10.40 & 2.58 & 13.77 & 3.60 & 1.70 & 86 \\
\hline VNM & 3.34 & 15.60 & 7.06 & 2.67 & 0.21 & 4.49 & 0.54 & 0.62 & 147 \\
\hline ZMB & 4.38 & 181.78 & 26.51 & 26.56 & 1.14 & 36.66 & 3.10 & 4.38 & 382 \\
\hline ZWE & 3.05 & 525.00 & 34.97 & 78.92 & 1.60 & 259.00 & 5.55 & 18.79 & 566 \\
\hline
\end{tabular}

Table 6: Descriptive statistics of GFD interest rates and the computed volatility. The volatility is based on the entire interest rate data available for that country. The last column (nobs) shows the number of consecutive months with non-missing data. 


\begin{tabular}{lcccccc}
\hline & 1 & 2 & 3 & 4 & 5 & Total \\
\hline Spot Change: $\Delta s$ & -1.028 & -0.184 & -1.845 & -3.797 & -2.935 & -1.955 \\
& $(13.03)$ & $(13.83)$ & $(14.32)$ & $(13.85)$ & $(46.44)$ & $(24.15)$ \\
$i^{*}-i$ & -1.594 & 0.0685 & 1.724 & 3.823 & 9.282 & 2.660 \\
& $(2.004)$ & $(1.882)$ & $(2.231)$ & $(3.326)$ & $(8.661)$ & $(5.820)$ \\
Excess Return: $r x$ & -2.713 & -0.143 & -0.207 & -0.0346 & 6.667 & 0.716 \\
& $(13.70)$ & $(14.03)$ & $(14.33)$ & $(13.68)$ & $(46.56)$ & $(24.48)$ \\
Volatility: $\sigma\left(i^{*}\right)$ & 0.301 & 0.308 & 0.426 & 0.548 & 1.079 & 0.533 \\
& $(0.134)$ & $(0.146)$ & $(0.212)$ & $(0.337)$ & $(0.979)$ & $(0.560)$ \\
\hline
\end{tabular}

Table 7: The whole sample of countries. This table shows for each portfolio 1 through 5 the average 3 -month change in log spot exchange rates (i.e. the appreciation of the foreign currency) $\Delta s$, the average interest rate relative to USD $i^{*}-i$, the average $\log 3$ month excess return $r x$, and the average volatility of interest rates $\sigma\left(i^{*}\right)$. All moments are annualized and in percentage points. In brackets are standard deviations. The average excess return and volatility of interest rates are plotted in the left panels of figure 4 .

\begin{tabular}{lcccccc}
\hline & 1 & 2 & 3 & 4 & 5 & Total \\
\hline Spot Change: $\Delta s$ & -0.805 & 0.627 & -0.776 & -5.063 & -9.395 & -3.082 \\
& $(11.85)$ & $(14.42)$ & $(19.64)$ & $(19.66)$ & $(21.48)$ & $(18.15)$ \\
$i^{*}-i$ & -2.292 & -0.570 & 1.082 & 3.438 & 11.60 & 2.653 \\
& $(2.416)$ & $(2.198)$ & $(2.024)$ & $(2.446)$ & $(7.739)$ & $(6.304)$ \\
Excess Return: $r x$ & -3.241 & 0.0177 & 0.244 & -1.677 & 2.506 & -0.430 \\
& $(12.47)$ & $(14.80)$ & $(19.86)$ & $(19.62)$ & $(21.24)$ & $(18.00)$ \\
Volatility: $\sigma\left(i^{*}\right)$ & 0.303 & 0.305 & 0.415 & 0.511 & 1.372 & 0.581 \\
& $(0.158)$ & $(0.142)$ & $(0.260)$ & $(0.383)$ & $(0.927)$ & $(0.621)$ \\
\hline
\end{tabular}

Table 8: The sample of countries that had interest rate data on January 1975. This table shows for each portfolio 1 through 5 the average 3 -month change in log spot exchange rates (i.e. the appreciation of the foreign currency) $\Delta s$, the average interest rate relative to USD $i^{*}-i$, the average $\log 3$ month excess return $r x$, and the average volatility of interest rates $\sigma\left(i^{*}\right)$. All moments are annualized and in percentage points. In brackets are standard deviations. The average excess return and volatility of interest rates are plotted in the left panels of figure 4 . 


\begin{tabular}{lcccccc}
\hline & 1 & 2 & 3 & 4 & 5 & Total \\
\hline Spot Change: $\Delta s$ & -0.443 & 1.060 & 0.0293 & -4.578 & -6.897 & -2.166 \\
& $(11.75)$ & $(17.22)$ & $(16.03)$ & $(13.65)$ & $(54.49)$ & $(27.87)$ \\
$i^{*}-i$ & -0.964 & 0.725 & 2.394 & 5.551 & 17.18 & 4.977 \\
& $(1.609)$ & $(1.764)$ & $(2.165)$ & $(2.630)$ & $(7.755)$ & $(7.571)$ \\
Excess Return: $r x$ & -1.555 & 1.753 & 2.385 & 0.926 & 10.66 & 2.834 \\
& $(12.11)$ & $(17.26)$ & $(15.92)$ & $(13.35)$ & $(53.12)$ & $(27.47)$ \\
Volatility: $\sigma\left(i^{*}\right)$ & 0.321 & 0.308 & 0.401 & 0.684 & 1.912 & 0.725 \\
& $(0.139)$ & $(0.131)$ & $(0.225)$ & $(0.397)$ & $(1.050)$ & $(0.800)$ \\
\hline
\end{tabular}

Table 9: The sample of countries that had interest rate data on January 1987. This table shows for each portfolio 1 through 5 the average 3 -month change in log spot exchange rates (i.e. the appreciation of the foreign currency) $\Delta s$, the average interest rate relative to USD $i^{*}-i$, the average $\log 3$ month excess return $r x$, and the average volatility of interest rates $\sigma\left(i^{*}\right)$. All moments are annualized and in percentage points. In brackets are standard deviations. The average excess return and volatility of interest rates are plotted in the left panels of figure 4 .

\begin{tabular}{lcccccc}
\hline & 1 & 2 & 3 & 4 & 5 & Total \\
\hline Spot Change: $\Delta s$ & -0.861 & 1.839 & -0.740 & -4.033 & -0.234 & -0.806 \\
& $(11.84)$ & $(14.77)$ & $(13.07)$ & $(13.27)$ & $(41.09)$ & $(21.91)$ \\
$i^{*}-i$ & -1.144 & 0.408 & 2.171 & 5.311 & 13.56 & 4.062 \\
& $(1.172)$ & $(1.040)$ & $(1.229)$ & $(1.928)$ & $(4.855)$ & $(5.781)$ \\
Excess Return: $r x$ & -2.152 & 2.220 & 1.373 & 1.218 & 13.80 & 3.292 \\
& $(12.14)$ & $(14.80)$ & $(12.92)$ & $(12.82)$ & $(40.06)$ & $(22.10)$ \\
Volatility: $\sigma\left(i^{*}\right)$ & 0.278 & 0.288 & 0.433 & 0.645 & 1.371 & 0.603 \\
& $(0.0753)$ & $(0.0918)$ & $(0.119)$ & $(0.187)$ & $(0.419)$ & $(0.461)$ \\
\hline
\end{tabular}

Table 10: The sample countries that had interest rate data on January 1995. This table shows for each portfolio 1 through 5 the average 3 -month change in log spot exchange rates (i.e. the appreciation of the foreign currency) $\Delta s$, the average interest rate relative to USD $i^{*}-i$, the average $\log 3$ month excess return $r x$, and the average volatility of interest rates $\sigma\left(i^{*}\right)$. All moments are annualized and in percentage points. In brackets are standard deviations. The average excess return and volatility of interest rates are plotted in the left panels of figure 4. 


\section{Figure 3}

\section{U.S. and Australian Interest Rates: Volatility and Spread}
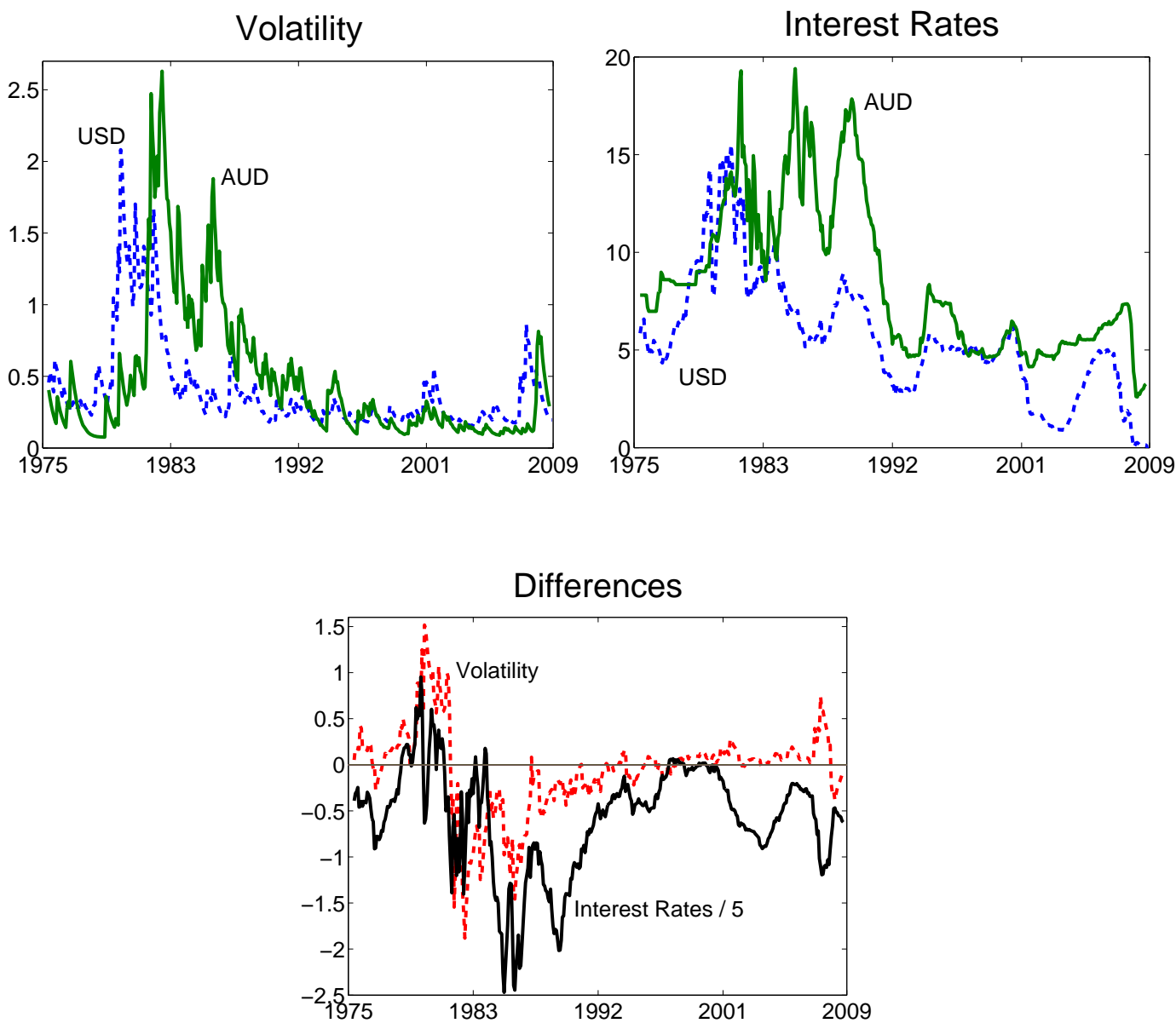

GARCH estimates of U.S. and Australian interest rate volatility appear in the upper left panel. Interest rates appear in the upper-right panel. U.S. data are the blue dashed-lines and Australian data are the green solid lines. The lower panel plots the differences, U.S. minus Australia from the two top panels. The red dashed line is the volatility difference and the the black solid line is the interest rate differential, divided by 5 . Lognormal models predict that, in the lower panel, the lines appear on opposite sides of zero, and are negatively correlated. By-and-large, the opposite seems to be true. The correlation is 0.52. Data source: 3-month interbank deposits from Global Financial Data (www.globalfinancialdata.com). 


\section{Figure 4}

\section{Average Volatility of Currency Portfolios}
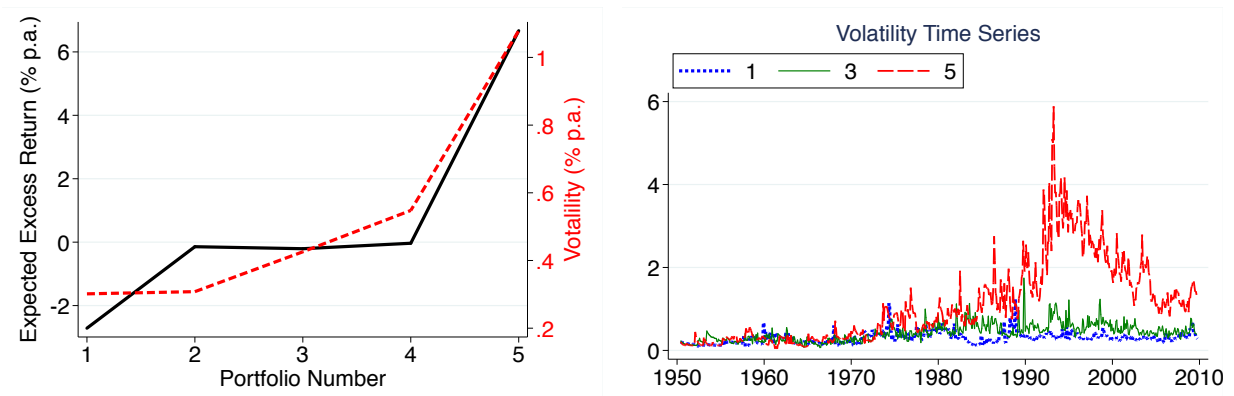

GFD interest rates, the whole sample.
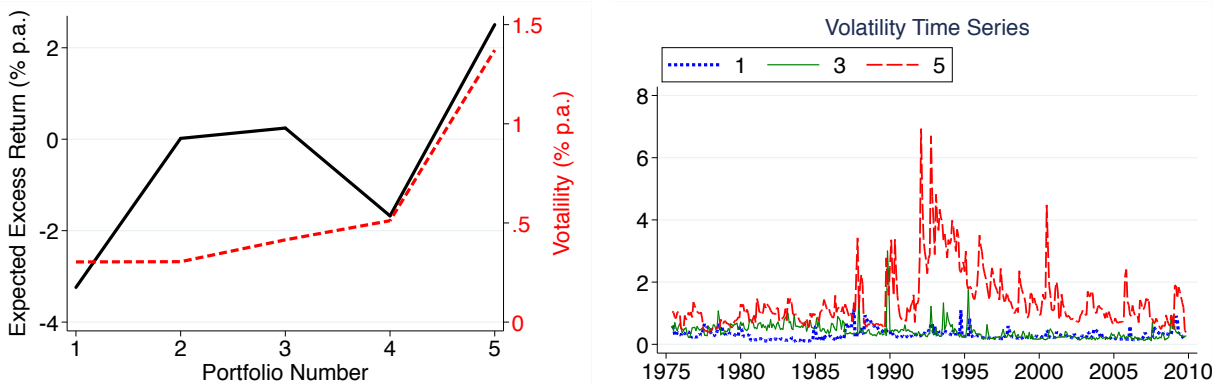

GFD interest rates, only the countries that had non missing data on January 1975. See tables 4, 5, and 6 to see which countries are in this sample. 

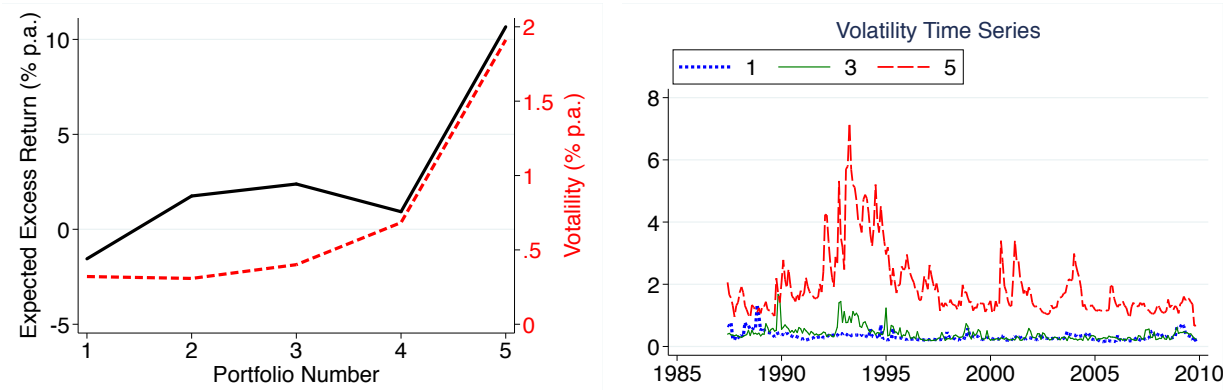

GFD interest rates, only the countries that had non missing data on January 1987 Jan. See tables 4, 5, and 6 to see which countries are in this sample.
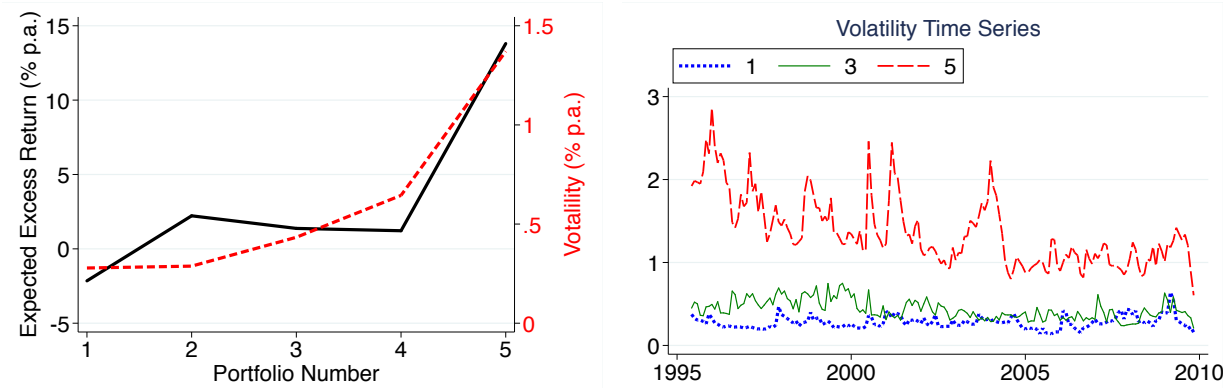

GFD interest rates, only the countries that had non missing data on January 1995 Jan. See tables 4, 5, and 6 to see which countries are in this sample. 


\section{Figure 5}

\section{Bilateral Currency Pairs}
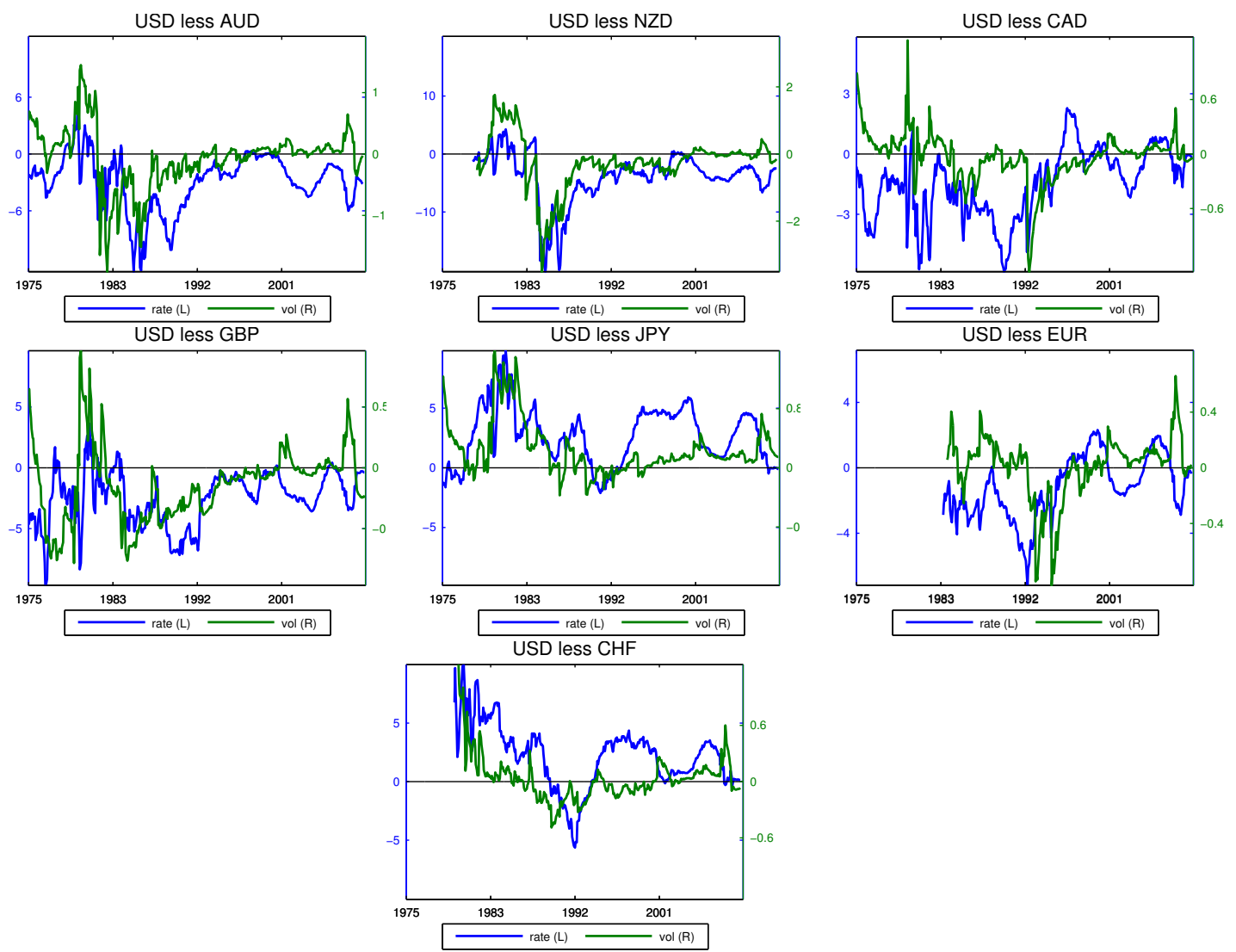

GFD interest rates: currency pairs 


\section{Figure 6}

\section{Data Source Comparison: GFD Versus FT/ICAP}
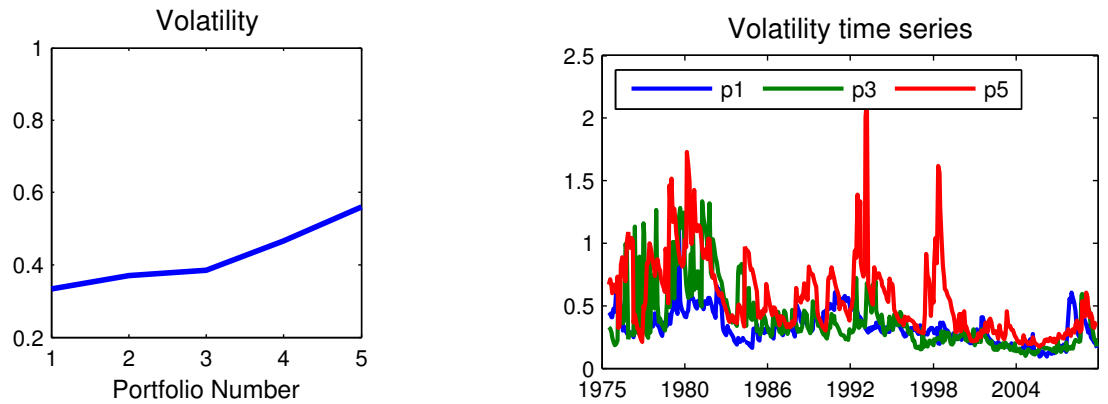

GFD interest rates, the same set of countries (and years) that is in the FT/ICAP interest rate data source in below figure.
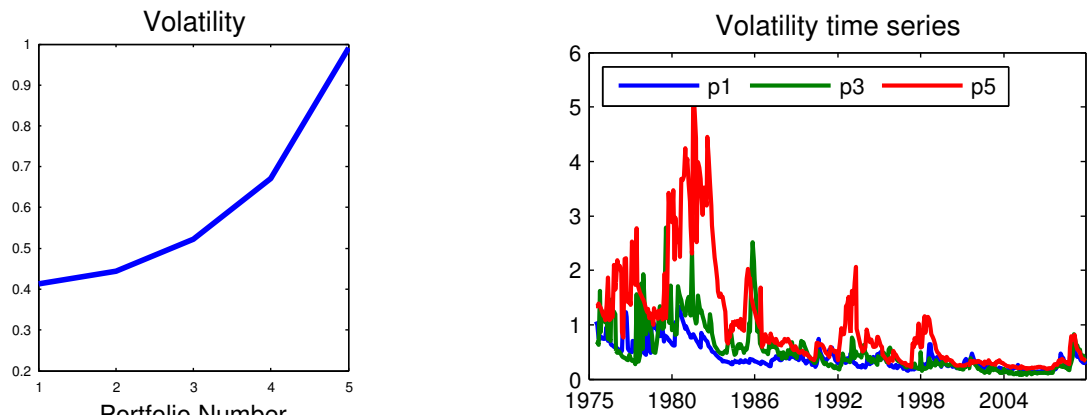

FT/ICAP interest rates, the whole sample.

The difference in volatilities between GFD and FT/ICAP interest rates (especially in early 1980's) is due to how different the GFD and FT/ICAP interest rates look even for the same country and the same date. Good examples were BEL, FRA, and ITA. So in figures 9 and 10, we replot above two figures without BEL, FRA, and ITA, after which the average volatility figure looks similar (in scale) between GFD and FT/ICAP. 

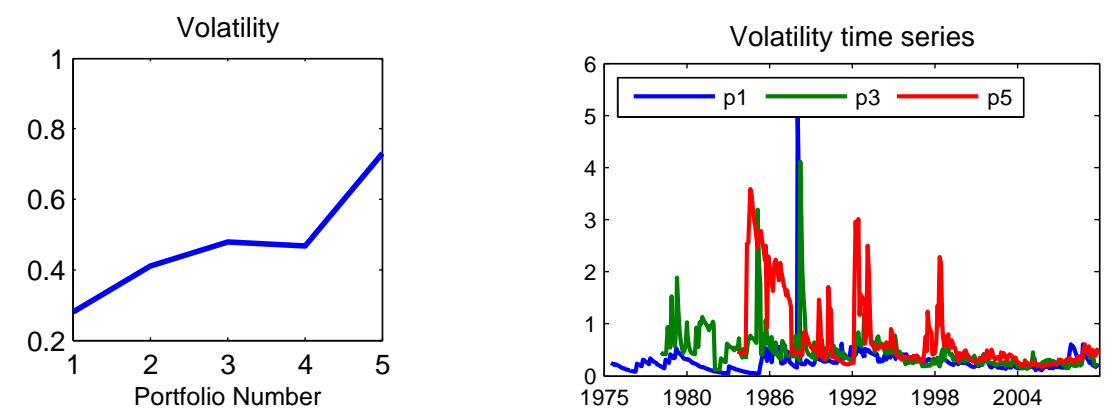

GFD interest rates, same as in figure 7 but without BEL, FRA, ITA
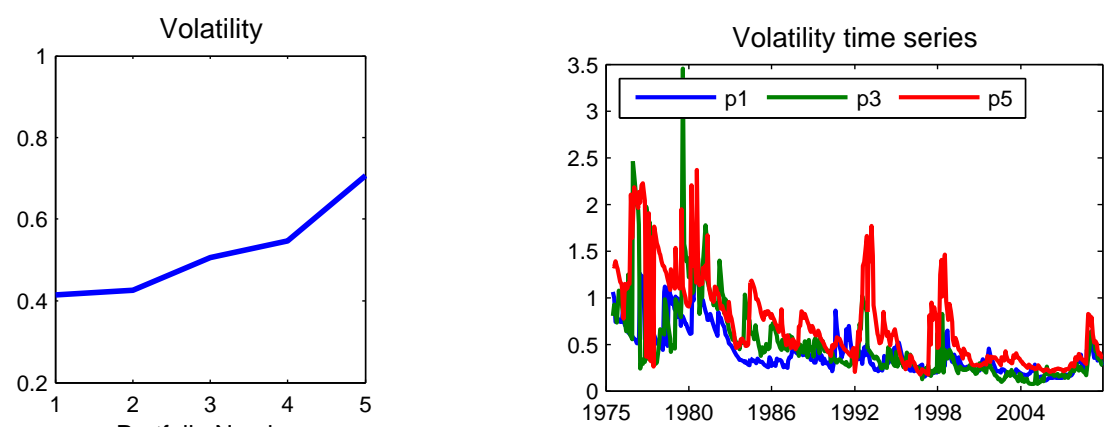

FT/ICAP interest rates, same as in figure 8 but without BEL, FRA, ITA 
Figure 7

Implied Volatility of Options on Interest Rate Futures

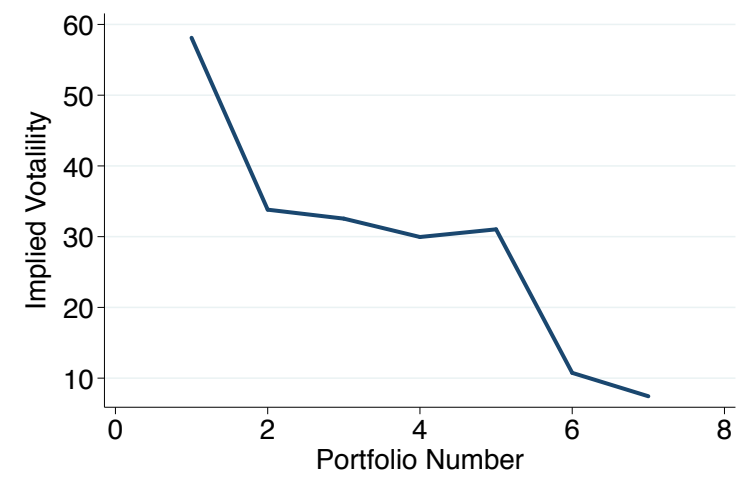



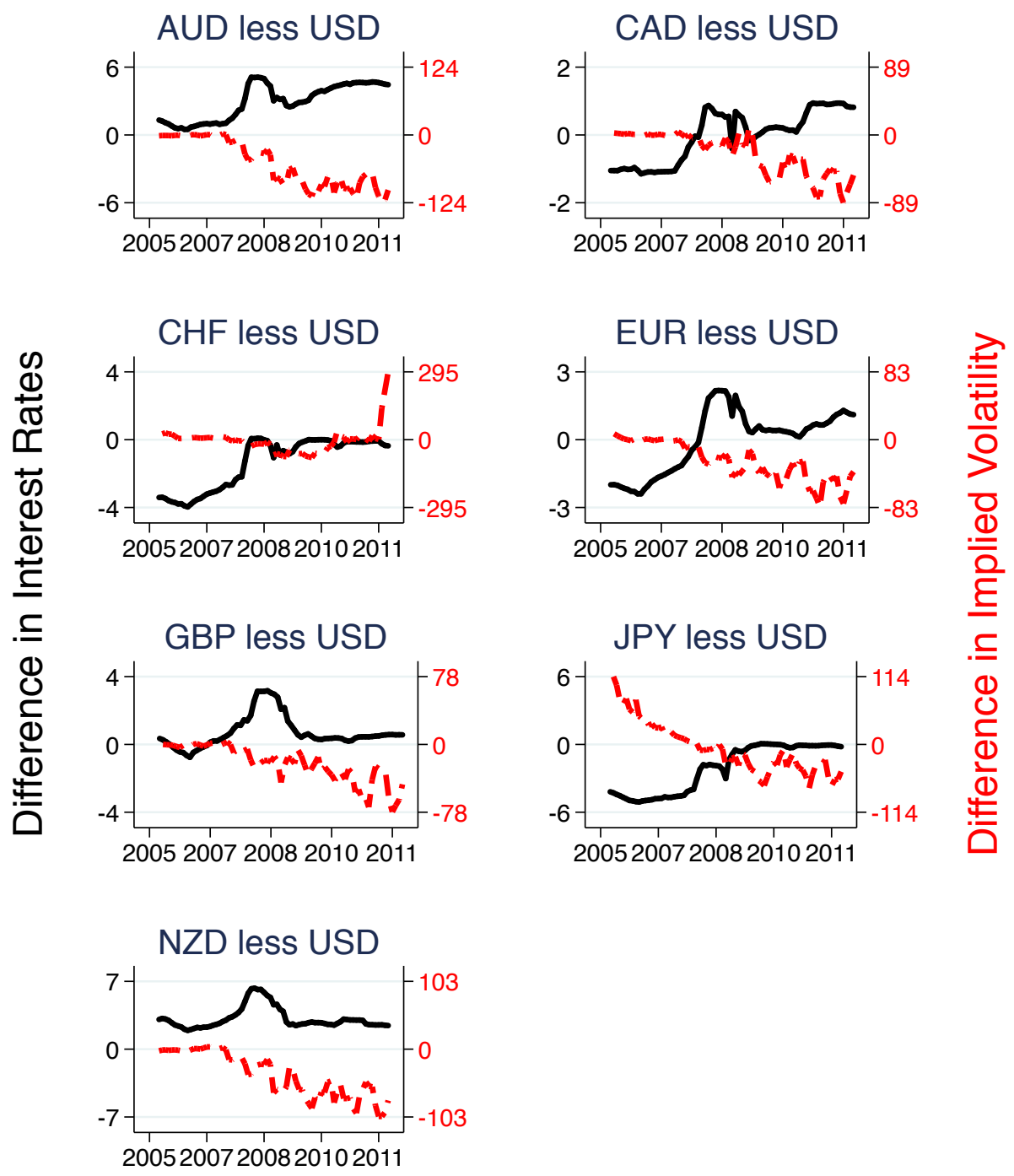